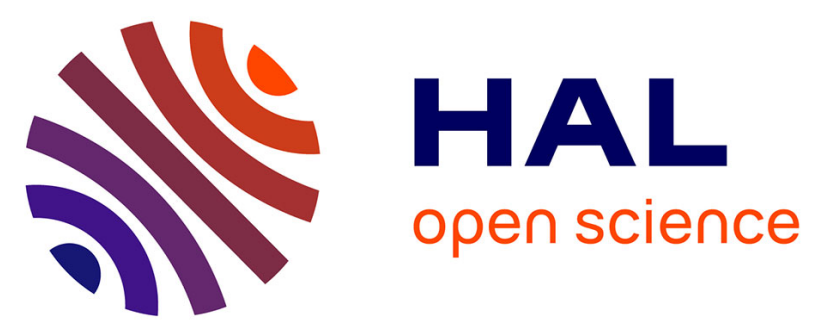

\title{
Climate-driven deposition of water ice and the formation of mounds in craters in Mars' North Polar Region
} Susan Conway, Niels Hovius, Talfan Barnie, Jonathan Besserer, Stéphane Le Mouélic, Roberto Orosei, Natalie Anne Read

\section{- To cite this version:}

Susan Conway, Niels Hovius, Talfan Barnie, Jonathan Besserer, Stéphane Le Mouélic, et al.. Climatedriven deposition of water ice and the formation of mounds in craters in Mars' North Polar Region. Icarus, 2012, 220 (1), pp.174-193. 10.1016/j.icarus.2012.04.021 . insu-02276816

\section{HAL Id: insu-02276816 https://hal-insu.archives-ouvertes.fr/insu-02276816}

Submitted on 3 Sep 2019

HAL is a multi-disciplinary open access archive for the deposit and dissemination of scientific research documents, whether they are published or not. The documents may come from teaching and research institutions in France or abroad, or from public or private research centers.
L'archive ouverte pluridisciplinaire HAL, est destinée au dépôt et à la diffusion de documents scientifiques de niveau recherche, publiés ou non, émanant des établissements d'enseignement et de recherche français ou étrangers, des laboratoires publics ou privés. 


\section{Climate-driven deposition of water ice and the formation of}

\section{2 mounds in craters in Mars' North Polar Region}

4 Susan J. Conway*

5 Laboratoire de Planétologie et Géodynamique de Nantes UMR-CNRS 6112 ,

6 Université de Nantes, 2 rue de la Houssinière, BP92208, 44322 Nantes, France.

$7 \quad$ susan.conway@univ-nantes.fr

8

$9 \quad$ Niels Hovius

10 Dept. of Earth Science, University of Cambridge UK, CB2 3EQ.

11 nhovius@esc.cam.ac.uk

12

13 Talfan Barnie

14 Dept.of Geography, University of Cambridge UK, CB2 3EN.

16 Jonathan Besserer

17 Laboratoire de Planétologie et Géodynamique de Nantes UMR-CNRS 6112 ,

18 Université de Nantes, 2 rue de la Houssinière, BP92208, 44322 Nantes, France.

20 Stéphane Le Mouélic

21 Laboratoire de Planétologie et Géodynamique de Nantes UMR-CNRS 6112 ,

22 Université de Nantes, 2 rue de la Houssinière, BP92208, 44322 Nantes, France. 
24 Roberto Orosei

25 Istituto di Astrofisica Spaziale e Fisica Cosmica (IASF), Italy

26

27 Natalie Anne Read

28 Dept. of Earth Science, University of Cambridge UK, CB2 3EQ.

29

$30{ }^{*}$ Corresponding author

31

32 Short title: A climatic origin of crater-ice in Mars' North Polar Region 
This paper explores the origins and evolution of ice-rich interior mounds found within craters of the north polar region of Mars. We present a systematic study of impact craters above $65^{\circ} \mathrm{N}$, and identify 18 craters that have interior mounds. At least eleven of these mounds are composed of water ice and geometric similarities suggest that dune-covered mounds may also have a water ice core. The mounds are found in the deeper craters in the north polar area and we suggest that these form a specific microclimate favorable for mound initiation and growth. It is likely that at least seven of the mounds have evolved as individual outliers, rather than conterminous with the main polar cap. Our observations suggest that the mounds are built up by atmospheric deposition, similar to that of the north polar layered deposits. Using a combination of remote sensing techniques enabling topographic, spectral, radar and image data analyses, we have documented the morphology, composition and stratigraphy of selected mounds. We advance and test four hypotheses for formation of these mounds: artesian outpouring from a deep aquifer, hydrothermal activation of ground ice, remnants of a more extensive polar cap, and atmospheric deposition on ice caps in meteorologically isolated locations. We propose that during periods when the perihelion was located in northern summer (most recently 10-25 ka before present) the microclimate in these craters retarded the sublimation of $\mathrm{CO}_{2}$ and water ice in northern spring, thus creating a cold trap for volatiles released as the seasonal cap retreated. This created a thick enough deposit of water ice to withstand sublimation over the summer and initiate a positive feedback leading to mound-building. Mounds without complete dune-cover may be in dynamic equilibrium with the ambient climate and show evidence of both present-day and past periods of erosion and aggradation. We conclude that the water ice mounds formed in deep impact craters in Mars' north polar region may contain sensitive records of past polar climate that may enhance our understanding of the $\mathrm{CO}_{2}-\mathrm{H}_{2} \mathrm{O}$ system in the polar regions. 
60 Highlights:

61 - 18 potentially ice-cored mounds were found in craters in Mars' north polar region.

62 - The stratigraphy of the mounds argues for deposition from the atmosphere.

63 - We argue many of them were deposited separately from the polar cap.

64 - The crater micro-environment is a potential explanation for mound initiation.

65 - These mounds are sensitive and important records of Amazonian climate on Mars.

66 


\section{Introduction}

68 The northern lowlands of Mars have long been considered an important reservoir for water.

69 It has been suggested that a northern ocean existed there in the Noachian and that water 70 may now be present deep in the local subsurface (e.g., Clifford, 1993; Clifford and Parker, 71 2001; Perron et al., 2007). More pertinently, the northern polar cap, with an estimated 72 volume of $1.3 \times 10^{6} \mathrm{~km}^{3}$ (Selvans et al., 2010) consists of a mixture of water ice and dust, 73 and a region of near-surface ground ice extends down to latitudes of $45^{\circ}$ (Byrne et al. 2009).

74 This was first shown by the hydrogen ion signature found by gamma ray spectrometry 75 (Feldman et al., 2004; Jakosky et al., 2005) and later supported by spectral signatures from 76 OMEGA (Bibring et al., 2005), the distribution of water surface frosts (Vincendon et al., 2010), the distribution of fluidized craters (Barlow and Perez, 2003) and the radar reflectivity properties of the surface (Mouginot et al., 2010), with ice found by the Phoenix lander (Mellon et al., 2008) providing a local ground truth. Seasonal cycles mobilize and redistribute these surface volatiles; principally those exposed on the polar cap. At present, the most noticeable seasonal change is the waxing and waning of the so called 'seasonal' polar caps, observable from Earth (e.g., Antoniadi, 1930). The northern hemisphere seasonal cap commonly extends down to $50^{\circ} \mathrm{N}$ and consists primarily of $\mathrm{CO}_{2}$ ice. It has a thickness of $0.5 \mathrm{~m}$ (Cull et al., 2010; Smith et al., 2001), and is sourced from the atmosphere by condensation of water followed by $\mathrm{CO}_{2}$ (Ivanov and Muhleman, 2001). Deposition occurs during the polar night and so has not been directly observed, but is thought to involve atmospheric condensation possibly as snow from ubiquitous cloud-cover. The spring recession is better characterized and it comprises a gradual northward retreat first of the $\mathrm{CO}_{2}$, then of the thinner water-ice annulus (Bibring et al., 2005; Wagstaff et al., 2008).

90 After recession of the seasonal volatile deposits there remain several substantial outliers 91 composed of water ice, which are spatially separated from the northern polar cap (Langevin 92 et al., 2005; Tanaka et al., 2008). Many of these ice bodies are found within craters, e.g., 
93 Korolev, Dokka and Louth. They are morphologically distinctive (Garvin et al., 2000), forming

94 an interior mound, which is convex-up and dome-shaped, with low local slopes and a moat that separates it from the crater walls. These mounds are distinct from an impact central peak, because they have convex-up positive relief in the center, often with a large volume placed asymmetrically within the crater. These mounds are generally assumed to be remnants of a previously more extensive northern ice cap (Garvin et al., 2000; Tanaka et al., 2008). Other possible origins include: upwelling from an underground aquifer (proposed but not supported by Russell and Head, 2002), activation of near-surface ground ice by impactinduced hydrothermal systems (a possibility considered for paleolake formation by Osinski et al., 2005; Rathbun and Squyres, 2002) and atmospheric condensation as individual outliers of the main cap (Brown et al., 2008). Although the latter invokes atmospheric deposition, as

104 for the polar cap, it differs significantly from the formation of polar cap remnants in that 1) a larger extent of the polar cap is not required and 2) more importance is given to

106 microclimatic effects inside the craters. Each of these formative mechanisms has important, 107 but different, implications for the dynamics of Mars' hydrosphere and climate. For example, if 108 they are indeed remnants of a formerly more extensive polar cap, then these mounds are 109 important records of both its extent and the conditions needed to preserve this ice. If sourced 110 from near-surface, or deep ground-ice, then the mounds give information on the distribution 111 of this ice and an indication of the volumes of water stored in the Martian crust. If the 112 mounds are supplied from deep sources, then this could support the presence of a deep, 113 global hydrosphere (Clifford, 1993). And if they are individual cap outliers, then the mounds 114 could be sensitive to climate perturbations and hence, their spatial distribution, morphology 115 and internal structure can help place constraints on recent climate.

116 The aim of this study is to explore the origins and evolution of interior mounds that are found 117 within some craters in the North Polar region of Mars. To this end, we document and 118 interpret the distribution, morphology and internal structure of these mounds, finding that the 
119 majority have likely formed by atmospheric deposition triggered by microclimatic effects

120 inside the host craters, separate from the main polar cap.

\section{2. Approach}

\section{$122 \quad 2.1$ Craters in the north polar basin}

123 We have based our impact crater survey on information from the Mars Orbiter Laser

124 Altimeter (MOLA) gridded data at 256 and 128 pixels per degree for the north polar region, 125 recording the locations and morphometric properties of all craters that are hydrologically 126 intact including craters with internal mounds. This survey is complete for craters with a 127 diameter $>5 \mathrm{~km}$, located north of $65^{\circ} \mathrm{N}$ (Barnie, 2006).

128 Impact craters were identified and digitized from MOLA data using a watershed analysis 129 technique aimed at delineating crater rims (cf. Stepinski et al., 2009). Each crater was given 130 a unique identifying number (Barnie, 2006; Hovius et al. 2009). Based on visual inspection of 131 the Thermal Emission Imaging System (THEMIS) and Mars Orbiter Camera Narrow-Angle 132 (MOC-NA) image mosaic data we identified craters containing dune fields. Dune fields were

133 identified by morphology where image resolution was sufficient and elsewhere by a 134 characteristic combination of high IR emission values in THEMIS IR daytime data and low 135 reflection of visible light in THEMIS VIS.

136 For all impact craters in our catalogue, we obtained elevation statistics from the MOLA digital 137 elevation model (DEM) including the maximum, minimum and range. The latter was used as 138 an estimate of the overall crater depth. The mean crater diameter was calculated by using $139 D=2 \sqrt{ }(A / \pi)$, where $D$ is the diameter and $A$ the area of the digitized rim polygon. This 140 method assumes the rim traces a circle and is not biased by topographic irregularities or 141 slight obliquity of the crater-form. The distance from a crater to the polar cap was measured 142 along the shortest straight line from the crater centroid to the edge of the contiguous Polar 143 Layered Deposits and Polar Ice Deposits as mapped by Tanaka et al. (2005). 
144 From our catalogue, we have isolated all craters containing raised central topography for

145 further analysis. The following additional criteria were applied:

146 1. To identify and exclude central peaks: North-south and east-west topographic 147 profiles were taken across these craters. Craters with central peaks were recognized 148 by the small extent $(<10 \%$ of the crater floor) and central position of the rise and the similarity of rise and crater wall albedo. These craters were not considered further.

2. For the remaining craters where the presence of dark dunes dominated the albedo of deposits within a crater, we applied a minimum relief of $150 \mathrm{~m}$ in our identification of mounds. This is the maximum relief of inner-crater dunefields measured outside of the survey area, and the cut-off eliminated only one mound from our survey (marked 332 in Fig. 2).

155 As the resulting mounds have geometries and surface attributes distinct from those of

156 central peaks, they were deemed to be depositional in origin. We digitized the limit of the

157 mounds using the topographic inflexion at the transition to concave-up crater topography as

158 a guide. Mound volume was estimated from surface topography and an extrapolation of the

159 crater floor below the mound (not including any estimate of a central peak). This involved

160 rotating through $360^{\circ}$ the power-law best fit to the median radial profile of the crater interior

161 (excluding any areas containing the mound) and differencing this estimated surface with the

162 MOLA topography to generate an isopach map for each mound. Using this map we also

163 calculated the mound asymmetry by measuring the horizontal offset between the center of

164 mass of the mound and the centroid of the crater rim.

\section{$165 \quad 2.2$ Mound Composition}

166 We have investigated the composition of surface materials on the crater mounds using data 167 from Mars Express' Observatoire pour la Minéralogie, l'Eau, les Glaces et l'Activité (MEX

168 OMEGA) imaging spectrometer and Mars Reconnaissance Orbiter's Compact 
169 Reconnaissance Imaging Spectrometer for Mars (MRO CRISM) targeted observations to

170 compute simple diagnostic ratios, including band depth and drop-off. OMEGA has a nearly

171 complete coverage of the north polar region at a spatial resolution of $\sim 3-7 \mathrm{~km} / \mathrm{pix}$ and also

172 covers selected areas at $0.5-1.5 \mathrm{~km} /$ pix. CRISM targeted observations have much lower

173 global coverage, but a very high spatial resolution of $15.7-19.7 \mathrm{~m} / \mathrm{pix}$. Both datasets

174 underwent standard atmospheric correction before spectral analysis ("volcano-scan"

175 algorithm, cf. Morgan et al., 2009). Although aerosol effects, not accounted for in this

176 correction, can be important in the north polar region (Vincendon et al. 2006; Vincendon

177 2008), the strong reflectivity of water and $\mathrm{CO}_{2}$ ice overwhelms the atmospheric effects

178 allowing reliable identification (Brown et al., 2010). Datasets from northern summer (Solar

179 longitude, $L_{s} 90-120^{\circ}$ ) were used to avoid seasonal $\mathrm{CO}_{2}$ surface frost, which could mask

180 any spectral signals from the material beneath (Bibring et al., 2005). The relative depth of

181 the absorption band at $1.50 \mu \mathrm{m}$ was used to estimate the water ice content. The depth of the

182 absorption band at $2.35 \mu \mathrm{m}$ was used to estimate the quantity of carbon dioxide ice (Brown 183 et al., 2010).

\section{$184 \quad 2.3$ Internal Stratigraphy}

185 The stratigraphy of mound materials was investigated with image data of surface outcrops 186 and radar data capturing the interior stratigraphy. Surface stratigraphic information was 187 obtained from images collected with THEMIS, High Resolution Stereo Camera (HRSC on 188 Mars Express), MRO Context (CTX) and MRO High Resolution Imaging Science Experiment 189 (HiRISE). All these images were either already geometrically corrected (HiRISE, HRSC), or 190 corrected using routines in the software ISIS3. Alignment with the MOLA DEM was manually

191 checked by verifying that local highs and local lows (e.g., crater rims, troughs) corresponded 192 between the image and the MOLA data. For specific examples we measured the distance 193 between the layers in plan-view. We assumed that the layers were approximately flat-lying 194 and thus corrected the measured distances to account for exposure angle (which makes the 
195 plan-view width of layers wider than their true thickness if the slope is less than $45^{\circ}$ ). This

196 was done by measuring the local slope, derived from MOLA topography, in the same

197 orientation as the layer thickness measurements. As the length scale of the MOLA-derived

198 slope is approximately ten times larger than that of the measured layers, the slope correction

199 introduces a degree of error, however it affects all measurements and no better source of

200 topography is available at present. For comparison purposes, we made equivalent

201 measurements of layer thickness in three exposures of the Polar Layered Deposits (PLD) in

202 HiRISE images PSP_010366_2590, TRA_000825_2665 and TRA_000863_2640 and one

203 exposure of the Basal Unit (BU) in HiRISE image TRA_000863_2640.

204 At selected locations we measured the junction angles of angular unconformities and/or 205 discontinuities exposed in outcrop, and ascertained younging directions from the layer 206 geometry. Where possible, dip and strike measurements of large-scale layering were made

207 by employing the geometric relationships between individual layers and 25 or $50 \mathrm{~m}$ contours

208 derived from the MOLA 512 and 256 pixels per degree data ( 115 and 230 m/pix,

209 respectively). Dips and strikes were measured over a length-scale of kilometers, so should

210 be considered as an area average value. We estimate the error in the dip measurement to

211 be $1-2^{\circ}$ as detailed below.

212 Uncertainty in the dip measurement derives from: 1) errors in the layer digitization, 2) human

213 errors in the distance measurements and 3) errors in the contours. We consider the layers to

214 be digitized to within 2 pixels of their actual location on the images $(50 \mathrm{~cm}$ for HiRISE and

$21512 \mathrm{~m}$ for CTX). We estimate the horizontal uncertainty of our distance measurements due to

216 human error as being between 10 and $50 \mathrm{~m}$, thus greater than the digitization uncertainty.

217 Horizontal errors of this magnitude (over lengthscales of kilometers) account for at worst a

$2182^{\circ}$ error in dip, but usually $\pm 1^{\circ}$. Contour errors can originate from interpolated pixels in the

219 MOLA DEM and misalignment of the DEM with the images. The interpolated pixels are a 220 relatively small source of error, because we performed these measurements over smooth, 221 continuous surfaces for which interpolation performs well, resulting in smooth contours with 
regular intervals. The potential horizontal misalignment between the images and DEM

223 dominates the error and we estimate it is of the order of 1-2 MOLA pixels (460 m at worst,

224 but more likely $100-200 \mathrm{~m}$ ). However this does not necessarily change the horizontal

225 distance between the contours (and thus the dip measurement) unless the slope changes

226 significantly over distances of $460 \mathrm{~m}$ or less in the region of measurement. For the majority

227 of measurements this was not the case. However, we took three examples where this was

228 the case (one in Korolev and two in crater 663) and shifted the contours in relation to the

229 images by $\pm 460 \mathrm{~m}$ in the direction of greatest change in slope. This simulated "worse-case"

230 misalignment resulted in an error in the measured dip angle of $\pm 1.5^{\circ}$.

231 We inspected all available MRO Shallow Radar (SHARAD) data intersecting craters with

232 mounds for signs of internal structure. Where we found structure within mounds we

233 performed clutter simulations using MOLA data to confirm that observed structures were not

234 due to surface topographic effects (Russo et al., 2008). To assess layer spacing and

235 thickness of mound deposits we converted the two-way-time into depth (cf. Plaut et al.,

236 2009) using a permittivity of 3.15 as previously used by Putzig et al. (2009) for the nearly

237 pure ice of the polar cap.

\section{3. Results}

2393.1 Northern plains craters morphology and distribution

240 We found 397 craters with a diameter $>5 \mathrm{~km}$ north of $65^{\circ} \mathrm{N}$. The depth-diameter relationship

241 for these craters is shown in Fig. 1. The relationship is described by $d=0.05 D^{0.98}$, where $d$ is

242 crater depth $(\mathrm{km})$ and $D$ is crater diameter $(\mathrm{km})$. For comparison, Garvin et al. (2000) found

$243 d=0.03 D^{1.04}$ for 109 impact craters north of $57^{\circ} \mathrm{N}$. These relationships differ significantly

244 from the global depth-diameter relationship for pristine craters as determined by Garvin

245 (2005). Compared to the polar depth-diameter relationships, the global depth-diameter 246 relationship predicts deeper craters for a given diameter, apart from for the very largest 
247 diameter craters. The same trend has been noted by Boyce and Mouginis-Mark (2005) and

248 Kreslavsky and Head (2006). This suggests that in the north polar area either, craters have

249 been subject to significant infilling, or that the properties of local substrate differ substantially

250 from the rest of Mars such that on formation impact craters are shallower compared to the

251 global population. From morphological evidence and the existence of a small population of

252 deep, young craters both Boyce and Mouginis-Mark (2005) and Kreslavsky and Head (2006)

253 conclude that craters in the north polar area are infilled.

254 At least 38 craters with $D>5 \mathrm{~km}$ contain dune fields. Dune fields were found in $28 \%$ of craters $>400 \mathrm{~m}$ deep (Fig. 1), but not in shallower craters. Such dune fields are not restricted to the polar region; we have found them in $24 \%$ of craters between $50^{\circ} \mathrm{N}$ and $65^{\circ} \mathrm{N}$. At these latitudes, the relief of dune fields above the crater floor usually does not exceed $150 \mathrm{~m}$ and the deposits usually cover relatively small areas within a crater. At higher northern latitudes some craters have extensive dune cover. This includes some craters with depositional mounds with relief in excess of $150 \mathrm{~m}$.

261 According to our criteria, eighteen craters were found to contain mounds (Fig. 2). They are located between $70^{\circ} \mathrm{N}$ and $82^{\circ} \mathrm{N}$, and none are smaller than $9.5 \mathrm{~km}$ in diameter (Table 1). Seven are adjacent to the polar cap and the furthest is located $>600 \mathrm{~km}$ from the cap. No craters with mounds were found between 65 and $70^{\circ} \mathrm{N}$. Many of the mounds consistently have high albedo in summer months (e.g., Armstrong et al., 2007; Garvin et al., 2000). However, many other craters in the north polar region that do not contain interior mounds also have this attribute (Calvin et al., 2009; Seelos et al., 2008; and informally by the MRO HiRISE team). Craters with mounds lie within the general depth-diameter distribution of craters in this region (Fig. 1), but for a given diameter they are relatively shallow compared to other craters of the same diameter. This can be accounted for only in part by the presence of a mound (predicted depths are given in Table 1 and shown on Figs. 1 and 3). Moreover, mounds are not found in all craters of any particular diameter and not all craters at a given 
273 latitude with a similar diameter contain a mound. In fact only $24 \%$ of all craters located

274 above $70.1^{\circ} \mathrm{N}$ with diameters greater than $9.5 \mathrm{~km}$ have interior mounds.

275 Figure 3 shows two representative examples of impact craters with an interior mound (all the 276 craters are shown in Fig. S1). Firstly, Dokka (388) with a clean ice mound, like Korolev (206) 277 and six other, smaller craters in our survey and secondly crater 811 with a mound-shape 278 similar to Dokka's, but entirely covered by dunes ("complete dune cover" on Fig. 2). Crater 279814 shares this characteristic. Four other craters have complete dune coverage, but their 280 mounds do not span the whole crater floor (480, 882, 904 and 934 - "dune covered mounds" 281 on Fig. 2). There are four mounds with dune partial cover, including one in crater 503, Louth. 282 In all cases dune patches coincide with the topographic high and only in the cases where 283 there is complete dune cover do the dunes ingress into the moat. Despite the different levels of dune cover the mounds share the following morphological characteristics (Fig. S1): flat or gently sloping summit, asymmetrical placement and a partial or complete moat separating 286 the mound from part or all of the crater wall.

287 At the scale of MOLA resolution ( 230 m) the mounds are smooth (except where dunes are 288 present, Fig. 3) and gently domed, with maximum local slopes of up to $34^{\circ}$ and a half-range modal slope for all the mounds of $0.9^{\circ}$ (mean of $3.6^{\circ}$ ). Mound relief ranges from $103 \mathrm{~m}$ to $1818 \mathrm{~m}$ above the current crater floor and mounds extend to within $13-1388 \mathrm{~m}$ below the 291 crater rim, filling their host to $9-89 \%$ of current crater depth from rim to floor (Table 1).

292 Pole-centered, radial swath profiles including the craters containing mounds illustrate the 293 local penetration depths of these craters into the crust and the relative heights of the mound 294 summits (Fig. 4). The longitudinal extent of the swaths was chosen to minimize the 295 longitudinal variation in elevation, so the penetration depth of the craters can be clearly seen. Figure 4 shows that the craters with mounds tend to be within the craters that penetrate to the deepest level for a given latitude and longitude region, but also that not all 
298 of the deeply penetrating craters have mounds. This figure also demonstrates that there is

299 no characteristic height up to which the mounds extend vertically.

300 Estimates of maximum ice thickness range from 94 to $1890 \mathrm{~m}$ with a mean of $605 \mathrm{~m}$, and 301 mound volumes range from 0.8 to $3850 \mathrm{~km}^{3}$, with a mean of $315 \mathrm{~km}^{3}$ (Table 1 and Fig. 5).

302 Our volume estimates are higher than those calculated by Garvin et al. (2000) for the largest craters. For example Garvin et al. (2000) listed volumes of 1356 and $463 \mathrm{~km}^{3}$ for the infill of

304 Korolev and Dokka, respectively and our corresponding estimates are 3850 and $1320 \mathrm{~km}^{3}$

305 (Table 1). The discrepancy can be accounted for by the difference of methods used in this 306 study and that of Garvin et al. (2000). Garvin et al. (2000) used single MOLA profiles to 307 determine a polynomial fit to the cavity interior and constrained the predicted depths using 308 empirical relationships between depth and diameter derived from 109 craters in the region.

309 We used all available MOLA data to provide information on the cavity shape and did not 310 constrain the crater depth.

311 Mounds are either completely or partially surrounded by a moat. Similar moats have been 312 found around concentric crater fill (CFF) near the Martian dichotomy boundary (Levy et al., 313 2010). However, CFF is flat-topped, rough at MOLA resolution ( 20-80 $\mathrm{m}$ of relief) and has 314 not been found to extend above $\sim 450 \mathrm{~m}$ below the crater rim. Westbrook (2009) described 31575 craters in the south polar region, which also contain mounds. These mounds are similar 316 to those described here in that they have a flat top, a distinct bounding slope (a moat), are 317 often offset from the crater center, 35 of them have exposed ice and layers and 17 are 318 topped by sand dunes. Notable differences include: the south polar mounds often have a 319 bounding ridge encircling their flat top, some exhibit flow features, some have multiple 320 superposed mounds, they are found down to lower latitudes $\left(60.8^{\circ} \mathrm{S}\right)$ and their host craters 321 are larger (diameters range from 18.6 to $114.1 \mathrm{~km}$, mean $45.1 \mathrm{~km}$ ). With the exception of the 322 southern polar craters, mounds such as the ones described here have not been reported 323 elsewhere on Mars. 


\subsection{Mound composition results}

325 Spectral data acquired by OMEGA (Fig. 6) show that there are very high water-ice concentrations (up to $\sim 0.7$ band depth) at the surface of the mounds in Korolev (206), Dokka

327 (388), Louth (503) and unnamed craters 544 and 579. The $\mathrm{CO}_{2}$ ice signal of from the

$3282.35 \mu \mathrm{m}$ band depth is less than 0.2 , hence at the limits of the detection using this method.

329 This indicates that the mounds are predominantly composed of water ice, similar to the

330 inferred composition of the north polar cap (Bibring et al., 2005). The other mounds in our

331 survey are too small to be resolved in low resolution OMEGA tracks and are not covered by

332 high resolution tracks. Where possible we have used CRISM targeted images to investigate

333 the composition of the mounds. For seven of the craters CRISM targeted images were not

334 available in the summer season, or of insufficient quality (obscured by clouds or other

335 atmospheric phenomena). Mounds that are completely covered in dunes had no discernible

336 water ice signal during northern summer. Instead their spectra resembled those of

337 background dust. For two mounds with partial dune cover (craters 663 and 769), a weak

338 water ice signal was detected in high albedo patches, but this signal was not significantly

339 stronger than that of the surrounding plains or crater interior. For crater 769 in particular the

340 spectra across both available images (FRT0000b546 and FRT0000cf48) were dominated by

341 dust, possibly due to the occurrence of small dust storms before these spectra were taken.

342 These storms were observed in Mars Color Imager (MARCl) images (Malin, et al., 2008.

343 MRO MARCI Weather Report for the week of 30 June 2008 - 6 July 2008. MSSS-40,

344 http://www.msss.com/msss_images/2008/07/09/ and MRO MARCI Weather Report for the

345 week of 13 October 2008 - 19 October 2008. MSSS-55,

346 http://www.msss.com/msss_images/2008/10/22/). However, by inspecting the map of

347 surface water ice abundance of Brown and Calvin (2010) derived from analysis of CRISM

348 mapping data, we were able to confirm the presence of water ice in craters:332, 515,577 ,

349663,697 and 795 , whereas 436,480 and 769 had no water ice signal. 
350 Spectral instruments (such as OMEGA and CRISM) can only penetrate the optical surface

351 and give information on the composition of the top few microns of the substrate in the case

352 of rock or dust, and the top few centimeters in the case of ice (Brown et al., 2010). Hence

353 the signals that we have observed could be from a thin surface veneer. However, other lines

354 of evidence support the hypothesis that the mounds are composed of a substantial thickness

355 of water ice, notably radar and stratigraphic arguments presented in Section 3.3 and also

356 thermal arguments in Section 4.5.1. Having confirmed the presence of water ice in eleven of

357 the crater mounds and having found striking morphometric similarities in all 18 mounds,

358 including craters completely covered by dunes, we propose that all these mounds have a

359 similar composition.

\section{$360 \quad 3.3$ Mound structure and stratigraphy}

361 Visible layering is common but not universal in mound deposits. It is picked out by reflectivity contrasts, probably due to differences in dust and/or frost concentration, or different resistance to erosion. Layers intersect the mound surface, forming contours on the gentle surface slopes, and outcrop geometries suggest that layering persists at depth within the mounds. We have mapped and measured spacing between layers on six crater mounds, three with partial dune cover and three without cover (Fig. 7). In addition, we have observed,

367 (but did not measure) layers in mounds in craters 697, 795, 544 and 577 located in close proximity to the polar cap. Layers were not observed in craters 934, 904, 882814,811 and 480 , where mounds are entirely covered by dunes. Crater 515 has no dunes, but no layers were observed, as in crater 436 which has partial dune cover. We have also found layering in a small mound in crater 332 (Fig. 2), which was excluded from our survey, because the

372 mound does not have sufficient relief $(>150 \mathrm{~m})$ to allow us to reliably distinguish it from a 373 dunefield, a criteria set out in our mound identification in Section 2.1.

374 Interior layering of mounds is exposed in areas with erosion. These areas are systematically 375 positioned on the south and east facing slopes of mounds (Fig. 7) and usually on the steeper 
than average slopes. These zones spatially overlap with significant proportions of water ice

377 in Fig. 6, in particular zones with water ice band depth > 0.7 water ice in Korolev (206),

378 Dokka (388) and crater 579. This strongly suggests water ice is the principal component in

379 the subsurface. We have estimated the thickness of 1438 layers in the six crater mounds

380 with extensive exposures. Where CTX images were used, HiRISE images within the same scene were used to confirm that layers thinner than those easily visible in the CTX images were not present. Layer thickness ranged from 0.007 to $12 \mathrm{~m}$, with an average of $0.42 \mathrm{~m}$ and a standard deviation of $1.55 \mathrm{~m}$ (Fig. 8). The layering observed in HiRISE images of the mound in Louth crater (503) is much finer than in all other mounds (median $0.15 \mathrm{~m}$ ). In all cases apart from the fine-scale layering in Louth crater (503) layers are laterally continuous on scales of $100-1000 \mathrm{~m}$.

Dips and strikes of layers were measured at 35 locations within mounds with extensive exposures (Fig. 7). Measured dips range up to $20^{\circ}$ with a mean of $\sim 5^{\circ}$. This is consistent with the distribution of surface slopes at sites with layer exposures (Fig. 9), with a mean of $4.4^{\circ}$ and a maximum of about $20^{\circ}$. The difference between layer dip angles and surface slope at any given location ranges from 0 to $9^{\circ}$, with a mean of $2^{\circ}$ and little skewing. This implies that the dip of the layers could be explained by draping of a topography similar to that of the present day outcrop sites. Figure 10 shows a detailed example of the interaction of layers with topography, highlighting that the dip directions are robust, even if the measured angles are subject to uncertainty (see Section 2.3 for a detailed discussion). The patterns of layer orientation are similar in all the mounds: strike orientations are similar to those of the present surface with dip directions away from the top of the mound and in some cases sub-parallel to crater-rim interior slopes. In all mounds with extensive exposures, layering is disrupted by unconformities. As an example, Fig. 10 shows unconformities observed within the mound in crater 579 . Younging of these deposits towards the top of the mound can be inferred from the truncation of layers that are located stratigraphically below

402 truncating layers (e.g., layer packet A (below) is truncated by layer packet B (above) in Fig. 
403 10). Unconformities were also observed in Louth crater (503) with the same apparent trend.

404 Although the younging directions are similar for coarse and fine-scale layering in this crater, 405 exposures of the two layer types are separate. Hence, we cannot tell if the fine layered 406 deposits are located stratigraphically beneath (i.e. older), or above (i.e. younger) the coarse 407 layered deposits. The fine-scale layers in Louth (503) pinch out laterally on the scale of 408 meters and have frequent discontinuities, which we interpret as evidence of small-scale 409 topographic drape. Recent wind erosion of these layer outcrops has caused the formation of 410 sharp, irregular groves or sastrugi (previously noted by Brown et al., 2008), draping of which 411 would give rise to the observed stratigraphy.

412 SHARAD radar data shows that the layered structure of mound deposits extends deeper into 413 the subsurface. We have found internal structures in the mounds of Korolev (206) and 414 Dokka (388) craters. Verified with clutter simulations, radargrams of the interiors of these 415 craters (e.g., Fig. 11) indicate that the main stratigraphy follows the contours of the present416 day mounds. Layer thinning is observed on the gently dipping south facing slope in Korolev 417 (Fig. 11). Layers deeper in the mound interior have a lower dip for both craters, but are more 418 undulating in the case of Korolev. The following vertical measurements are directly 419 dependent on the assumed permittivity, as we have chosen pure water ice they are 420 maximum estimates (lower water ice contents would give reduced lengths). The minimum 421 spacing between reflectors in the radargram for Korolev is estimated to be 6-18 $\mathrm{m}$ with 422 approximately $\sim 20$ distinct reflectors visible over a thickness of $\sim 2.5 \mathrm{~km}$. The reflectors 423 picked up by radar instruments, such as SHARAD are generally acknowledged to delineate 424 packets of layers (Phillips et al., 2008; Putzig et al., 2009), rather than individual beds. The 425 last return corresponds to $\sim 3.9 \mathrm{~km}$ below the rim for Korolev, which compares favorably to 426 the estimated depth of $\sim 2.9 \mathrm{~km}$ from the relationships of Garvin et al. (2000) and $3.1 \mathrm{~km}$ 427 from our results, implying that the permittivity of the mound material does not differ much 428 from that of water ice, as was assumed in the depth correction. Thus, the SHARAD data 
confirms that layering continues throughout the mound, and that the layered material is likely

430 to consist mainly of water ice over the entire depth of fill.

431 Other, smaller crater mounds did not produce internal radar reflections, probably because

432 they do not contain sufficiently continuous layering or sufficiently strong dielectric contrasts.

433 In the along and across track directions reflectors must be at least $300-1000 \mathrm{~m}$ and $1500-$

$4348000 \mathrm{~m}$ long, respectively, to produce a strong radar return (Alberti et al., 2007). The mound

435 in crater 579 is likely to be sufficiently large to allow radar detection of internal structures, but

436 it had no SHARAD coverage, at the time of writing.

437 Given that layering appears to be pervasive within the mound deposits, we can surmise that 438 mound patches without exposed layering in Fig. 7 represent areas with present-day 439 deposition of water ice.

\section{4. The origin and evolution of the crater-mounds}

441 Eleven, possibly eighteen intermediate and large impact craters at high northern latitudes on

442 Mars have interior mounds consisting mainly of water ice. These ice-filled craters are some

443 of the deepest depressions in their surroundings. The mounds have a smooth, convex-up

444 shape, often asymmetrically placed within their crater and inclined to the south, surrounded

445 by a distinct moat. They have internal layering with unconformities indicating upward 446 younging of deposits and an alternation of phases of deposition and erosion. Layers appear

447 to drape over the extant topography of the mounds. This layering may be pervasive down to 448 the base of the deposits where they rest on the crater floor. Any explanation of the origin 449 and evolution of the crater mounds must address these key features. In this section we 450 consider four distinct scenarios of mound formation after a brief exploration of controls on 451 the present day geometry of the mounds. 


\subsection{Present-day form}

453 The surface form and position of the mounds inside the craters may be determined by the mechanism that drives mound formation, or it could be due to subsequent processes changing the initial shape of the deposit. Only in the former case does the mound geometry contain information about the formative mechanism. Therefore we consider briefly whether post-depositional erosion alone can account for the mound shape. Using a radiation balance approach, and including effects of shadowing caused by the crater walls, atmospheric scattering, temperature-dependent re-radiation from the surface and conduction, Russell et al. (2004) have demonstrated that a north-south asymmetry and an exterior moat can be developed from an initially flat ice body inside a crater over limited time under current orbital configuration. They showed that any east-west asymmetry cannot be produced from radiation alone, but could be explained by aeolian processes, as winds coming off the cap are deflected longitudinally by planetary vorticity. Figure 12 shows the asymmetrical placement of the mounds within our studied craters. Mounds proximal to the cap have a westward displacement from the crater center and this matches the prevailing easterly wind direction as indicated by dune slip faces (Tanaka and Hayward, 2008). Mounds closer to the cap tend to be more asymmetric than those further away. These observations suggest that these mounds are primarily shaped by the wind, which is known to be stronger near the cap (e.g., Howard, 2000). Further away from the cap the mounds are placed obliquely or orthogonal to the prevailing wind, suggesting a stronger influence of radiation. The orientation of mound patches with exposures of internal layering in six of the craters (Fig. 7) matches this explanation. Dominance of south-facing layer exposures can be attributed to

474 directionality of incident radiation, and east- or west-facing exposures can be related to 475 regional winds. Together the asymmetry of the mounds and the orientation of layer 476 exposures suggest that radiation-driven ablation and wind work together (with different 477 relative magnitudes) to shape the existing ice deposits. This likely obviates the need to 
478 invoke a primary formation mechanism to explain the present-day large-scale morphology of 479 crater mounds.

\section{$480 \quad 4.2$ Remnant of a more extensive polar cap}

481 As a first possible scenario of mound formation it has been proposed that the interior mound 482 of Korolev and similar features elsewhere could be erosional remnants of a formerly more 483 extensive polar cap (Fishbaugh and Head, 2000; Garvin et al., 2000; Tanaka et al., 2008), 484 along with outliers such as Olympia Mensae. Specifically, Tanaka et al. (2008) have suggested that the Korolev deposit and those similar to it could be related to stratigraphic unit "ABb1", the Polar Layered Deposits (PLD). A previously larger extent of the cap

487 (including the PLD and the Basal Unit beneath) is surmised based on the large erosional scarps at the current margins of the cap, however the precise spatial extent is not known. With reference to the position of outliers, Fishbaugh and Head (2000) and Johnson et al. (2000) have proposed that the cap extended symmetrically down to $80-75^{\circ} \mathrm{N}$. Rodríguez et al. (2010) have argued that an extension of the PLD down to $\sim 60^{\circ} \mathrm{N}$ and subsequent retreat could account for the distribution of Late Amazonian pedestal craters. If the polar cap was more extensive, then there is general agreement that it must have occurred under higher obliquity conditions than at present (which favors migration of ice to lower latitudes), but the exact timing is debated.

The PLD was laid down in the Amazonian as sub-horizontal layers from regular (possibly seasonal) cycles of atmospheric deposition of water-ice mixed with small and variable amounts of dust, producing regularly spaced layers with differing albedo of meter to tens of

499 meters in thickness. Layers are extremely laterally continuous (e.g., Fishbaugh and 500 Hvidberg, 2006) and angular unconformities occur mainly in association with the spiral 501 troughs (Putzig et al., 2009; Smith and Holt, 2010; Tanaka et al., 2008). These layers are observed to generally dip at less than $1^{\circ}$ from image (Milkovich et al., 2008) and SHARAD radar data. Even layers draping trough walls do not have dips in excess of $1^{\circ}$ (e.g. Fig. $3 e$ of 
504 Smith and Holt, 2010). The maximum total deposit thickness is estimated to be $1800 \mathrm{~m}$ from

505 MARSIS radar data (Selvans et al., 2010). These deposits are thought to provide a record of

506 past climate, similar to the polar ice caps on Earth (e.g., Cutts 1973; Laskar et al., 2002;

507 Milkovich and Head, 2005; Milkovich et al., 2008). Estimates of past accumulation rates are

508 on the order of $0.5 \mathrm{~mm} / \mathrm{yr}$ (e.g., Laskar et al., 2002), or lower (Perron and Huybers, 2009).

509 The modern polar cap is undergoing both accumulation, as shown by the burial of craters in

510 fine-grained ice (Banks et al., 2010) and the lack of dust accumulation on its surface, and

511 erosion, as shown by the exposure of coarser grained ice with lower albedo at scarps

512 (Langevin et al., 2005).

513 Underlying a large part of the PLD is the Basal Unit (BU) or Planum Boreum Cavi unit 514 (ABbc) using the nomenclature of Tanaka et al. (2008). This unit is characterized by a lower 515 albedo compared to the PLD and is inferred to be rich in sandy material containing a variable

516 quantity of volatiles. Layers have variable regularity and cross-bedding and a thickness up to 517 decameters (Herkenhoff et al., 2007). Layers can be laterally discontinuous particularly on 518 the $100 \mathrm{~m}$ scale with frequent angular unconformities. Lighter-toned layers are more 519 resistant and thought to be more ice-rich. The BU is hypothesized to be of Middle to Late 520 Amazonian age, originating from aeolian deposition, sometimes in the form of ice-cemented 521 dunes. The dip angle of these layers has not been measured, but cross-bedded layers are 522 locally steeper than strata of the PLD. The maximum deposit thickness is estimated to be $5231100 \mathrm{~m}$ from MARSIS data (Selvans et al., 2010). It is possible that the BU, like the PLD has 524 been more extensive in the past.

525 If the mounds in our study are remnants of a larger, continuous polar deposit then they might be expected to have a similar stratigraphy. Measured layer thicknesses on the mounds are generally within the range reported for the PLD (Milkovich et al., 2008). According to our own assessments of $\sim 350$ layers over three outcrops (see Section 2.3 for details) the PLD have layer spacing of 0.5 to $40 \mathrm{~m}$ with a median of $4.7 \mathrm{~m}$ and $\mathrm{BU}$ between 0.05 and $7.0 \mathrm{~m}$ with a 
530 median of $1.4 \mathrm{~m}$, presenting no statistically significant difference with layering in crater

531 mound deposits (Fig. 8). The only exception is the fine-scale layering found in the central 532 part of the mound in Louth crater (503), which is significantly and consistently finer than 533 layers measured anywhere else. However, the frequency of discontinuities (e.g. Fig 10) in 534 the mounds in general seems to be greater than within the PLD (where they are rare). This 535 implies that the mounds have experienced more erosive episodes. In addition, mound 536 layering is laterally less continuous, but this could be due to limited exposure compared to 537 the polar cap. Layer dip angles in the mounds are up to $20^{\circ}$, which is much greater than the $538 \sim 1^{\circ}$ dips measured by Milkovich et al. (2008) for the PLD. Moreover, it would be expected in 539 the case of PLD-like deposition that layers should drape the crater walls, dipping gently 540 towards the center of the crater, with a flat lying central part as observed for craters 541 emerging from the polar cap (see Fig. 4 of Rodríguez et al., 2010). This contrasts with the 542 observed outward dip of mound layers that extends into the mound interior, indicating growth 543 from a central core (Figs. 7, 11).

544 Preservation of the mounds in crater interiors during cap-retreat has been attributed to the 545 shielding effect of the crater geometry (Garvin et al., 2000). For a given crater 546 depth/diameter ratio, then, the ice preservation rate should depend to a degree on the 547 radiation regime which changes with latitude. Confirmation of this link comes from the south 548 polar region, where the volume of ice bodies inside craters has been observed to decrease 549 away from the pole (Russell et al., 2003). However, there exists no such relationship either 550 between the mound volume as a proportion of the total cavity volume (a least squares linear 551 fit gives $R^{2}$ of 0.302 and $p$-value of 0.011 ), or the absolute mound volume and distance from 552 the polar cap in the northern hemisphere $\left(R^{2}\right.$ of 0.058 and $p$-value of 0.806$)$. This could 553 indicate a) a different origin for the mounds in the south compared to the north, or b) different environmental factors determining mound survival between the two hemispheres (e.g., geometric shielding is less important than, for example, wind patterns in the north). 
556 On balance we feel that stratigraphic, structural and volumetric evidence are not compatible

557 with the theory that crater mounds distal from the current polar cap formed as part of a larger 558 contiguous PLD or BU deposit. In particular this applies to Louth (503), Dokka (388), Korolev 559 (206), craters 579, 663769 and 436, but we cannot rule out the role of a slightly more extensive polar cap in the formation of mounds located proximal to the present-day polar cap deposits.

\subsection{Impact-driven water release}

563 Our second scenario involves the mobilization of water from permafrost. It has been hypothesized that relatively long-lived hydrothermal systems could be driven by the heat released by a meteorite impact (Abramov and Kring, 2005; Osinski et al., 2005; Rathbun and

566 Squyres, 2002), or that the seismic energy of an impact can mobilize water/permafrost

567 (Harrison et al., 2010). This mechanism was suggested for the formation of a channeled scabland extending from the ejecta blanket of Lyot crater located at $55^{\circ} \mathrm{N}, 330^{\circ} \mathrm{W}$ and a band of paleo crater lakes (El Maarry, et al., 2010), both south of our study area. The northern plains region of Mars should be particularly susceptible to the mobilization of

571 ground ice as it is abundant in the shallow sub-surface. The possibility of impact-induced

572 hydrothermal systems in permafrost-rich ground on Mars was first suggested by Brakenridge 573 et al. (1985). In this process the impact melt sheet of larger impact craters contains sufficient 574 heat energy to melt the surrounding permafrost and water contained in topographic highs drains into the crater hollow. The resulting lake freezes at the surface, retarding evaporative loss. Additional water can be sourced from subsequent hydrothermal circulation, driven by

577 temperature gradients within the surrounding regolith, which draws water into the crater

578 interior. Once the system has cooled sufficiently water starts to drain downwards out of the 579 crater lake and eventually a frost front may propagate upwards from the subsurface, leaving 580 a solid body of ice in the crater interior. 
581 Rathbun and Squyres (2002) have shown that impacts creating craters with a diameter less

582 than $7 \mathrm{~km}$ have insufficient energy to sustain a crater lake. This cut off is relatively close to 583 the observed lower diameter limit for craters with mounds of $\sim 9.5 \mathrm{~km}$. For larger craters, the 584 presence or absence of a mound should then depend on the time since impact, and we would expect to find mounds preferentially in the youngest craters. At received cratering rates (e.g., Hartmann and Neukum, 2000), over our study area (excluding the area of the cap), an impact such as Dokka (51 km diameter) could be as old as several hundreds of millions of years and Korolev $(80 \mathrm{~km})$ over $1 \mathrm{Ga}$. It is unlikely that relatively small ice bodies would have survived for this length of time, especially given that the polar cap is believed to

590 be no older than 4-5 Ma (e.g. Levrard et al., 2007). There are not sufficient craters in this 591 size range without a mound to confirm, or refute the impact heat theory, although we note that Lyot crater, a large, $215 \mathrm{~km}$ diameter crater just south of our study area, has no

593 evidence of water ponding in its interior either as a mound, or a desiccated lake (Harrison et 594 al., 2010; Russell and Head, 2002).

595 In this scenario mound size should have no particular spatial trend, assuming that the same 596 amount of sub-surface water is available throughout the polar region, but depend primarily 597 on the energy of impact. As crater diameter is a proxy for impact energy, we might expect it 598 to scale with the mound volume (an approximation of the amount of water released).

599 Although the percent of the crater cavity in-filled by the mound does not correlate well with 600 the diameter of the crater, the absolute volume of infill increases with the crater diameter, 601 apparently as a power law with the form $(0.04 \pm 0.09) D^{2.8 \pm 0.2}$ with an $R^{2}$ of 0.983 and a $p$ 602 value of $9.6 \times 10^{-11}$ where the uncertainty attached to the estimation of mound volume has 603 not been taken into account. However, the hydrothermal system is unlikely to have sustained 604 a hydraulic head permitting significant flow above the plains surrounding impact craters. In 605 fact, Rathbun and Squyres (2002) estimated a lake depth of $300 \mathrm{~m}$ for a $7 \mathrm{~km}$ diameter 606 crater and of $\sim 1 \mathrm{~km}$ for a $180 \mathrm{~km}$ diameter crater (which is almost twice the diameter of 607 Korolev 206). Several craters in our survey have mounds that significantly exceed these 
608 values. Additional elevation of the mounds (of up to $0.5-0.8 \mathrm{~km}$ in some cases) would have

609 to be accounted for, for example by invoking frost-heaving processes active in the waning

610 period of hydrothermal activity, similar to pingo formation on Earth, as suggested by

611 Sakimoto et al. (2005) and Bacastow and Sakimoto (2006).

612 It is perhaps most difficult to reconcile our observations of mound deposit stratigraphy with

613 the requirements of the scenario of impact-driven water release. Creation of the mounds by

614 this mechanism implies that the mounds have geologically the same age as the impact that

615 created their host crater, and are formed in a single event. Moreover, the mechanism could

616 give rise to complex, out-of-sequence layering as periods of hydrothermal injection into an

617 ice covered lake should cause under-plating and thermal erosion, similar to that of aufeis

618 (Gillespie et al., 2005). This could be followed by freezing of the water from both the top and

619 the bottom, producing frost-heave features, folding and faulting when the hydrothermal system wanes. Water circulated through the subsurface at high temperatures may also

621 contain impurities consisting of salt and sediment that could be frozen into the deposits.

622 These expected characteristics contrast with our observation of regular, upward younging

623 layers of relatively pure ice, without major faults, or folds. In Louth crater (503) small-scale

624 layering has more folds, but is still relatively regular. Finally, the pervasive presence of large625 scale discontinuities in the mound deposits suggests an evolution involving multiple events.

626 This, and lack of correspondence with proposed crater lake dimensions are all problems for 627 this mechanism.

\section{$628 \quad 4.4$ Artesian flow}

629 The third scenario of mound formation appeals to the presence of deep-seated faults below 630 impact craters (e.g., Christeson et al., 2001). These faults could tap into a deep aquifer 631 confined by the cryosphere that is hypothesized to underlie the north polar plains (as 632 predicted by Clifford, 1993; Clifford and Parker, 2001; Clifford et al., 2010), providing a 633 conduit to the surface for the confined water. Water would come to the surface at times 
634 when the cryosphere enlarges and impinges on the aquifer producing sufficient confining

635 pressure. This mechanism has been proposed for the creation of crater lakes at lower

636 latitudes by Newsom et al. (1996). Upwellings would not necessarily occur at the same time

637 as the impact event and could occur many times, producing a layered stratigraphy as

638 observed. Assuming that the top of the aquifer is located on a single level, then mounds

639 should be found in large craters with large fault systems, but also smaller craters located on

640 low-lying topography. Our results show this trend, where mounds are found in craters which

641 tend to penetrate to the deepest local elevation (Fig. 4). If the aquifer is fully connected and

642 the mounds formed at the same time then the mounds should extend up to a similar

643 topographic elevation, equal to the hydraulic head. This is not the case. If flow rates are low,

644 then it might be expected that smaller mounds should be found in craters with a base

645 located at higher absolute elevation. We do observe a very weak negative relationship

646 between the inferred elevation of the crater base and both relative (linear) and absolute

647 mound volume (exponential), with $R^{2}$ values of 0.006 and 0.37 respectively and $p$-values of

$648 \quad 0.31$ and 0.003 respectively.

649 As in the hydrothermal hypothesis mound formation would involve processes akin to those

650 occurring in pingos. This, together with wind and/or radiation ablation could give rise to 651 doming of the mounds. The internal stratigraphy of such mounds should be complex. Water 652 could pond on the surface and gradually freeze as a lake system, or could inject underneath 653 pre-existing ice. Subsequent pulses would deform, fracture and fold, possibly under-plating 654 the roof, or breaking through to the surface, filling topographic hollows. Potentially the age of 655 the ice could increase, or decrease towards the center, depending on the dominant 656 emplacement mechanism. Ice interior to the mounds should have many discontinuities, folds 657 and faults. Such complexity is not characteristic of the mounds in our study, which display 658 regular layering, large-scale discontinuities, minor folding and no faulting. The fine-scale 659 layering in Louth crater (503) is the only example that shows sufficient complexity to fit with 660 this model, but it is the exception, rather than the rule. Interestingly, the mound in that crater 
661 is placed very eccentrically, as would be expected from the peripheral position of impact fault

662 systems. However, neither there nor elsewhere have we found spectroscopic evidence for

663 the presence of salts in mound deposits, which is expected for upwelling water sourced at

664 depth. In addition, there appears to be a discrepancy between the observed distribution of 665 crater mounds and the geometry of the putative deep aquifer (Clifford, 1993). The aquifer is 666 thought to be located deepest close to the polar cap, where surface temperatures are 667 lowest, but there we have found mounds in several craters of limited diameter and depth. It 668 is possible that the aquifer is located at shallower depths than proposed by Clifford (1993) 669 very near to the pole, due to water being supplied from the base of the polar cap (e.g., 670 Longhi, 2006). Away from the polar cap, the cryosphere is thought to thin southward, making 671 mound or lake formation more likely in this scenario. The lack of evidence for hydrological 672 activity in Lyot crater (Russell and Head, 2002; Harrison et al., 2010) is at odds with this 673 expectation. Despite the mounds occurring in the deeper penetrating circumpolar craters, 674 inconsistencies in stratigraphy, composition, position and distribution argue against artesian 675 flow from a deep aquifer as a formative mechanism for these mounds.

\section{$676 \quad 4.5$ Crater microclimate}

677 Our fourth hypothesis calls on microclimate phenomena associated with crater topography 678 for growth of ice mounds from atmospheric deposition. We start our exploration of this 679 mechanism with some observations of temperature and albedo in and around craters in the 680 north polar region.

\section{$681 \quad$ 4.5.1 Craters as cold traps}

682 The temperature and albedo evolution of ice mounds in Korolev and Dokka through the 683 Martian year have been reported by Armstrong et al. (2005) and Kuti (2009). These mounds 684 are consistently $\sim 10 \mathrm{~K}$ cooler than ice-free terrain at the same latitude for most of the year, with an accentuated daytime difference of $\sim 20-40 \mathrm{~K}$ in summer months (Fig. 13). On these 
crater mounds, surface temperatures remains close to the water frost point throughout the

687 year (particularly at night). In other craters without ice (an example is given in Fig. 13),

688 temperatures inside and outside the craters are very similar for most of the year. These

689 observations suggest that the presence of ice modulates local near surface temperatures in

690 crater interiors. A minimum thickness of ice of several meters at the surface may be required

691 to produce this effect (Armstrong et al., 2005). So how did this initial ice layer come about in

692 the craters with mounds, and how and when does/did this volatile deposition occur?

693 The following thermal, spectral and image data reveal that crater cavities may enhance the

694 deposition and/or preservation of volatiles at the present day. Viking Infrared Thermal

695 Mapper (Kieffer 1977) and Thermal Emission Spectrometer (TES; Titus et al. 2001)

696 observations have shown temperatures below the $\mathrm{CO}_{2}$ sublimation point inside craters

697 during winter. These cold spots are unlikely to represent real surface temperatures, but

698 could be caused by cloud formation and thus possibly increased deposition of $\mathrm{CO}_{2}$ ice

699 (Ivanov and Muhleman, 1999). In agreement with these observations, we also observe that

700 apparent crater floor temperatures with and without ice mounds are up to $10^{\circ} \mathrm{K}$ below those

701 outside the crater between $L_{s}=240-320^{\circ}$ (Fig. 13).

702 We have examined published OMEGA data (Appéré et al., 2011) and HiRISE and CTX 703 images for presence of surface ice at latitudes greater than $60^{\circ} \mathrm{N}$ around the $\mathrm{L}_{\mathrm{s}}=60^{\circ}$ crocus 704 date, when $\mathrm{CO}_{2}$ frost is receding. The OMEGA data show that crater floors remain covered 705 in water ice for approximately $5^{\circ}$ of $L_{s}$ after the main seasonal cap has retreated to higher 706 latitudes (Figures 5-8 Appéré et al., 2011). These deposits then degrade to an annulus 707 around the crater rim, before disappearing. HiRISE and CTX images show that crater floors 708 rarely have any remnant high albedo ice deposits after the crocus date. They do show, 709 however, that high albedo patches remain after the crocus date on north-facing crater slopes 710 (Fig. 14B) and sometimes as E-W 'plumes' outside the crater (Fig. 14A). Many of these 711 patches disappear in the summer, but some remain as shown in CRISM analyses performed 712 by Seelos et al. (2008). These authors have hypothesized that the 'plumes' are a result of 
713 wind-driven, orographic deposition of water ice. Hajigholi et al. (2010) monitored seven

714 craters at $>55^{\circ} \mathrm{N}$ and also noted crater interiors were favored sites for ice deposition. These

715 observations show that crater floors are not presently sequestering $\mathrm{H}_{2} \mathrm{O}$ or $\mathrm{CO}_{2}$ deposited in

716 the seasonal polar cap under present day conditions.

717 If atmospheric deposition is the driving process in which layers are constructed, then to start 718 mound formation, ice build-up in winter months on the crater floor must outstrip sublimation

719 in spring and summer. The presence of high-albedo ice deposits throughout the year may 720 then locally suppress near surface temperatures and form a long-lived cold trap for $\mathrm{H}_{2} \mathrm{O}$. It is 721 possible that the ice layer needed to trigger further build-up is provided by a hydrothermally 722 induced crater lake, or the remnant of a more extensive cap deposit. Below, we examine a scenario that does not involve an external start, and is instead entirely climate-driven.

\section{$724 \quad$ 4.5.2 Reduced sublimation of water ice in craters}

We have demonstrated that at least seasonally all craters trap water ice. However, this does not explain why only some craters in the near polar area host mounds and why others do not. We suggest that this is because of differing preservation potentials between the craters, which are determined by differing rates of sublimation. Factors, such as shadowing within the crater, differences in surface thermophysical properties, atmospheric temperature, atmospheric pressure and the wind regime, play a role in defining the sublimation rate.

731 The higher the surface temperature the more rapid the sublimation, so cooler temperatures

732 favor the preservation of ice mounds. The surface temperature is controlled by insolation 733 (and thus shading) and surface themophysical properties. If we consider shadowing alone, 734 water ice should be preserved on all north-facing crater walls rather than on crater floors and mounds should therefore have an off-center nucleus, positioned on the north-facing slope. In

736 the craters where we have studied the stratigraphy the nucleus of the mound is located on

737 the crater floor and not all craters have mounds, hence this factor alone does not explain our 
observations. We cannot determine the surface material albedo and thermal inertia of the

739 craters prior to mound deposition; hence we cannot definitively say what role these

740 thermophysical properties played.

741 The atmospheric pressure at the base of a crater is greater than on the surrounding plains

742 (due to altitude) and this can act to reduce sublimation by free convection (e.g., Ingersoll,

743 1970). As the mounds are often found in craters that penetrate deeply into the crust (Fig. 4),

744 this may be one factor that could help to explain the mound distribution. However, other

745 factors must be playing a role, because not all deeply penetrating craters have mounds.

746 Wind speed and its saturation level also play a key role in sublimation, with strong, dry winds

747 enhancing forced sublimation (e.g., Ingersoll, 1970). Given this, it might be expected that

748 craters with mounds should be located away from the strong summer katabatic winds, but

749 we observe no systematic placement of craters with mounds with respect to these winds

750 (see maps in Massé et al. 2012, Ewing et al., 2010 and Howard, 2000). At a smaller scale

751 craters generate their own wind systems. Fenton and Hayward (2010) noted a peculiar

752 "bullseye" dunefield morphology in craters close to the southern polar cap, and attributed it

753 to inward flowing local katabatic winds. We see the same morphology inside many of the

754 craters with mounds and inside other craters in the area, indicating the strong influence of

755 local winds. The topography of each crater would have different effects on these wind

756 patterns, but with the data available we find no systematic pattern to explain why some

757 craters have mounds and others do not. To precisely determine the role of local-scale winds

758 in triggering mound formation would require a full meso-scale climate model (e.g. Spiga, et 759 al. 2011), which is outside the scope of this paper.

\section{$760 \quad$ 4.5.3 Initiation and mound building}

761 We envisage the following sequence of events (Fig. 15) for the initiation and evolution of 762 mound building: 
763 1) In winter condensation of water ice is followed by the condensation of $\mathrm{CO}_{2}$ intermixed with

764 a smaller fraction of water ice. The micoenvironment inside the crater interior causes 765 additional condensation of volatiles over the winter period, resulting in a thicker layer of both $766 \mathrm{CO}_{2}$ and $\mathrm{H}_{2} \mathrm{O}$ in the crater floor than on surrounding plains.

767 2) The $\mathrm{CO}_{2}$ layer is first to sublimate in spring. This process is driven by direct insolation, but 768 also draws heat from the surrounding atmosphere, and this maintains a low temperature in 769 the crater interiors $(\sim 150 \mathrm{~K})$. Simultaneously, water ice is sublimating at lower latitudes and 770 this water vapor can condense back on to the sublimating $\mathrm{CO}_{2}$ deposits at higher latitudes 771 (e.g. Appéré et al. 2011). The thicker layer of $\mathrm{CO}_{2}$ deposited on the crater floor, and lower 772 local temperatures cause the crater floor to defrost later than the surrounding landscape. 773 This means that the process of re-condensation of water vapor can continue for longer and 774 in particular while $\mathrm{H}_{2} \mathrm{O}$ is sublimating from the landscape immediately surrounding the crater.

775 3) Once the surrounding landscape has completely defrosted and the $\mathrm{CO}_{2}$ sublimation in the 776 crater has finished, there remains a layer of water ice condensed over winter and additional, 777 re-condensed water ice layer.

778 4) The sublimation of this remaining water ice is retarded by the microclimate of the crater 779 interior (likely pressure and wind effects). Due to the high albedo of the deposit both free and 780 forced sublimation will also be slowed due to the lower atmospheric temperature above the 781 deposit (further enhanced if the deposit is thick). A thick layer (with high thermal inertia) 782 might permit re-condensation during the night if any sublimation has occurred.

783 5) Once a "thick" layer has been built ( 1-4 m required according to Armstrong et al., 2005)

784 this creates a positive feedback, whereby the high albedo and high thermal inertia form a 785 cold trap which produces net accumulation over the course of a year (Fig. 13). Then, water 786 vapor delivered to the crater at almost any time of year could freeze onto the existing 787 deposit, and progressive build-up of an ice mound would ensue.

788 Atmospheric deposition would give rise to upward younging stratigraphy, with regular 789 layering, reflecting cyclical deposition on seasonal, but more likely much longer timescales. 
790 Changes in the balance of deposition and ablation could cause alternation of aggradation

791 and decay of the deposits, recorded in (angular) unconformities within the mound

792 stratigraphy. During an initial build up phase, deposits are expected to line the crater interior,

793 but solar irradiation and directional ablation by winds would eventually cause the formation

794 of a moat and give the deposit a characteristic mound shape. Further volatile deposition

795 would drape the mound topography, dipping outward from an accumulation center, and

796 following any erosional detail in the pre-existing ice surface. All of these expectations are

797 matched by our stratigraphic observations.

\section{$798 \quad$ 4.5.4 Timing}

799 At present, craters are not initiation points for mound building, nor is mound building very

800 rapid. Assuming that current maximum deposition rates are similar to those on the north

801 polar cap, 3-4 mm/yr (Banks et al., 2010), a mound such as the one in Korolev would take

$802 \sim 500 \mathrm{ka}$ to form when deposition is uninterrupted. Orbital forcing of climate is important on

803 this time scale. Using a global climate model and different orbital parameters Levrard et al.

804 (2007) showed that obliquity (axial tilt, $\sim 124$ ka cycle) is the primary orbital control on ice

805 accumulation in the polar region. Low obliquity favors polar cap accumulation and obliquities

806 greater than $30^{\circ}$ can destabilize ice in the whole polar region (which last occurred at

$807 \sim 0.4 \mathrm{Ma})$. Another important feature is the precession cycle ( 51 ka), a combined effect of

808 the eccentricity and longitude of the perihelion. The orbit of Mars is elliptical, so that northern

809 hemisphere spring is the longest season, followed by northern summer, winter and the

810 shortest season is autumn, the present-day location of the perihelion. Thus, northern winters

811 are comparatively short and warm, and summers are long and cool. If the perihelion is

812 located in northern summer, then winters become longer cooler and the summer becomes

813 short and relatively hot. It is the length of the seasons, rather than their relative temperature,

814 that governs ice accumulation at obliquities less than $25^{\circ}$ (Levrard et al., 2004; Levrard et

815 al., 2007). As the obliquity has been relatively stable over the last $500 \mathrm{ka}$, precession cycles 
816 dominate. We suggest that mound triggering and building may be favored when the

817 perihelion is located in summer or autumn, allowing a longer period of winter deposition and

818 a long spring period when volatiles are delivered from the receding seasonal cap and the

819 main polar deposits. This situation last occurred between 10-25 ka before present

820 (Montmessin et al., 2007). These cycles could account for the large angular unconformities

821 that we observe. Further modeling is required to accurately ascertain orbital parameters that

822 are favorable to mound building.

823 If the mounds are indeed formed by atmospheric deposition, then their overall form and

824 internal stratigraphy are controlled by climatic conditions. If their timescale of adjustment is

825 relatively quick compared to the timescale of climate change then they should provide a 826 stratigraphic record of recent climate changes, driven by changes in Mars' orbital 827 configuration.

\section{$828 \quad$ 4.5.5 Other ice outliers}

829 We surveyed the outlying high albedo deposits that are not located within craters to

830 ascertain if there was a common formation mechanism with the mounds inside craters. The

831 majority of these deposits are mostly thin (they show underlying impact craters of $\sim 500 \mathrm{~m}$

832 diameter with an expected rim height of $\sim 25 \mathrm{~m}$ ) and only around Olympia Mensae (between

$833 \sim 95-135^{\circ} \mathrm{E}$ and $\sim 73-80^{\circ} \mathrm{N}$, Fig. 2, marked "OM") do they reach thicknesses of $>100 \mathrm{~m}$. The

834 presence of relatively thin outliers located between Dokka, Korolev and the Olympia Undae dunefield (between $\sim 150-240^{\circ} \mathrm{E}$ and $\sim 75-80^{\circ} \mathrm{N}$ latitude) has been previously attributed to the

836 presence of polar deposits underlying this area (Fishbaugh and Head, 2000). Tanaka et al.

837 (2008) classified these high albedo deposits as 'ABb ${ }_{4}$ ' or Planum Boreum 4 unit, which is the

838 unit that caps the present polar cap, and suggested that these deposits are recent (last

$83921.5 \mathrm{ka}$ ) and relatively thin. Recent radar data has confirmed that the BU extends beneath

840 the Olympia Undae dunefield (Selvans et al., 2010), making it quite plausible that thin

841 deposits extend further north. These high albedo deposits occur where dunes are not 
842 present, so it could be that they are accumulations resulting from the exposure and resulting

843 cold-trap effect of BU deposits.

844 The presence of thicker deposits in the Olympia Mensae area is more difficult to explain.

845 They occur as discrete patches with steep boundary scarps with up to $\sim 20^{\circ}$ slopes and

846 thickness of up to $350 \mathrm{~m}$, but more generally around $100 \mathrm{~m}$. They are located latitudinally

847 between and to the east of Louth (503) and crater 579. This area is of relatively high

848 elevation compared to the same latitude elsewhere around the pole. Three of the outcrops

849 are elongate in the E-W direction and have layer exposures in all orientations, consistent

850 with wind erosion rather than radiation as the primary shaping mechanism. The Olympia

851 Mensae deposits have visually very similar stratigraphy to the crater mounds in terms of

852 layer spacing and presence of low-angle unconformities, but only have very low dips $\left(<1^{\circ}\right)$

853 and no draping layers (Fig. 16). They have almost $100 \%$ exposure of the layers, which

854 implies they are currently undergoing retreat. This is supported by Brown et al. (2011), who

855 suggest that sublimation in the Olympae Mensae region might be the main source of the

856 water which masks the $\mathrm{CO}_{2}$ seasonal cap during its spring regression. This suggests these

857 outliers unlike the crater mounds have not undergone significant recent deposition and

858 therefore their evolution is somewhat different to that of the ice mounds inside craters. The

859 questions of how their deposition was triggered and their previous extent are left open as

860 targets for future investigation.

\section{5. Conclusions}

862 We have identified and studied 18 inner-crater mounds in Mars' north polar region that have

863 an origin different from the central peaks normally found in complex craters. They are

864 restricted to craters with a diameter $>9.5 \mathrm{~km}$ located at latitudes $>70^{\circ} \mathrm{N}$. Two of these crater

865 mounds consist largely of water ice according to radar data and nine others have substantial

866 water ice at the surface as observed in spectral data. We infer by similarity of form and

867 location that the other mounds are also composed of water ice. Their large-scale 
868 morphology, flat topped with a circumferential moat, can be explained by ablation of volatiles

869 by solar radiation and wind, leaving no indication of the formation mechanism.

870 The formation of these mounds by either impact-induced hydrothermal circulation or artesian 871 upwelling is inconsistent with the generally unfolded and unfaulted, regular layering with 872 upward younging stratigraphy exposed on mound surfaces. Moreover, ice layers drape the 873 existing topography on at least six of the mounds, implying growth from a central core. This

874 is inconsistent with these mounds being erosional remnants of a previously more extensive 875 polar cap. It is plausible that this form of growth is shared by eight other mounds that are not 876 directly adjacent to the present polar cap. For the four mounds abutting the present polar 877 cap we cannot rule out an origin by cap retreat.

878 Ice accumulations can be maintained or grow by cold trapping when they have attained a 879 minimum thickness required to form a negative thermal anomaly that persists throughout the 880 year. This minimum condition can be achieved in one of three ways: a frozen paleo-lake 881 from an impact hydrothermal system, a remnant of a more extensive polar cap, or 882 atmospheric deposition driven by microclimate processes inside the crater. We have no 883 observational evidence to support any of these initiation mechanisms, but we have explored 884 in more detail the possibility that mound formation is entirely due to the microclimatic characteristics of deep impact craters at high northern latitudes.

886 Mounds are found in deeply penetrating craters where atmospheric pressures are high 887 compared to the areas surrounding the crater. This suppresses ice sublimation, but not all 888 deeply penetrating craters have mounds, so other climatic factors, such as wind regime, 889 must be playing a role. We suggest that microclimatic effects act to suppress the sublimation 890 of seasonal ice in springtime, both increasing its lifetime and creating a cold-trap onto which 891 volatiles released from the surrounding landscape during warm seasons can condense. It is 892 likely that during periods when Mars' orbital perihelion was located in northern summer, 893 longer winters have allowed enhanced deposition of volatiles, while the potential for 894 sublimation was limited by the brevity of summers. Under these conditions, which last 
895 occurred 10-25 ka ago, enough ice may have built up in deep crater interiors to start a

896 positive feedback permitting mound building due to the formation of long lived cold trap 897 above bodies with high albedo and thermal inertia. The main supply of water vapor to these 898 cold traps may be the seasonal cap with secondary input from katabatic winds flowing from 899 the polar cap during spring and early summer.

900 Where mound surfaces are not clad by dunes, the fact that layers are seen to be exposed at

901 the surface indicates recent or ongoing erosion in these areas. However, elsewhere the lack 902 of visible layering can be attributed to recent deposition of ice draping the mound 903 topography. Hence, the mounds are currently undergoing change, likely driven by changes 904 in the local climate. Changes in climate may shift and resize the depositional and erosion 905 areas, explaining the complex pattern of discontinuities visible in exposed mound 906 stratigraphy. If this interpretation is correct, then the crater mounds may be sensitive

907 recorders of climate change in the north polar area, located in closest proximity to the main 908 source of volatiles on present day Mars. Further investigation of their stratigraphy and 909 dynamics may yield new insights into the past and present $\mathrm{H}_{2} \mathrm{O}$ and $\mathrm{CO}_{2}$ cycles of the 910 planet.

\section{Acknowledgements}

912 Firstly we thank Colin Dundas and Adrian Brown for their thorough and thoughtful reviews,

913 which greatly improved the manuscript. We thank Edwin Kite, Simon Dadson, and Dimitri

914 Lague for their additions and critique. Additional support provided by the Earth Science

915 Department at Cambridge University was essential in completing this work. We are indebted

916 to the late Ali Safaeinili who created the code enabling estimation of the SHARAD time to

917 depth conversion. Marion Massé provided useful discussion on CRISM and OMEGA

918 spectral data. Many thanks to Rosalyn Hayward for giving permission to use her data on

919 dunefields in the north polar region and Lori Fenton for useful discussion regarding bullseye

920 dunes. Thomas Appéré provided insightful comments on polar seasonal processes. 


\section{References}

922 Abramov, O., Kring, D. A., 2005. Impact-induced hydrothermal activity on early Mars. J. Geophys. Res. 110 (E12), doi:10.1029/2005je002453.

924

925

926

927

928

929

930

931

932

933

934

935

936

937

938

939

940

941

Alberti, G., Dinardo, S., Mattei, S., Papa, C., Santovito, M. R., 2007. SHARAD radar signal processing technique. IWAGPR 4th International Workshop on Advanced Ground Penetrating Radar, Naples, Italy.

Antoniadi, E. M., 1930. La Planète Mars. Herman, Paris.

Appéré, T., B. Schmitt, Y. Langevin, S. Douté, A. Pommerol, F. Forget, A. Spiga, B. Gondet, J. P. Bibring (2011), Winter and spring evolution of northern seasonal deposits on Mars from OMEGA on Mars Express, J. Geophys. Res. 116(E5), E05001, doi:10.1029/2010JE003762.

Armstrong, J. C., Titus, T. N., Kieffer, H. H., 2005. Evidence for subsurface water ice in Korolev crater, Mars. Icarus. 174 (2), 360-372.

Armstrong, J. C., Nielson, S. K., Titus, T. N., 2007. Survey of TES high albedo events in Mars' northern polar craters. Geophys. Res. Lett. 34, doi:10.1029/2006GL027960.

Bacastow, A. L., Sakimoto, S. E. H., 2006. Martian North Polar Crater Morphology: Implication for an Aquifer. Lunar Planet. Sci. 37. Abstract 2239.

Banks, M. E., Byrne, S., Galla, K., McEwen, A. S., Bray, V. J., Dundas, C. M., Fishbaugh, K. E., Herkenhoff, K. E., Murray, B. C., 2010. Crater population and resurfacing of the Martian north polar layered deposits. J. Geophys. Res. 115 (E8), doi:10.1029/2009JE003523. 
Barlow, N. G., Perez, C. B., 2003. Martian impact crater ejecta morphologies as indicators of the distribution of subsurface volatiles. J. Geophys. Res. Planets. 108 (E8), doi:10.1029/2002JE002036.

Barnie, T. D., 2006. Placing constraints on the origin of the ice fill of north polar ice impact craters on Mars using impact crater and ice fill morphology. Master's Thesis, University of Aberystwyth, pp. 114.

Bibring, J. P., Langevin, Y., Gendrin, A., Gondet, B., Poulet, F., Berthe, M., Soufflot, A., Arvidson, R., Mangold, N., Mustard, J., Drossart, P., 2005. Mars surface diversity as revealed by the OMEGA/Mars Express observations. Science 307 (5715), 15761581.

Brakenridge, G. R., Newsom, H. E., Baker, V. R., 1985. Ancient hot springs on Mars: Origins and paleoenvironmental significance of small Martian valleys. Geology 13 (12), 859862.

Brown, A. J., Byrne, S., Tornabene, L. L., Roush, T., 2008. Louth crater: Evolution of a layered water ice mound. Icarus 196 (2), 433-445.

Brown, A. J., Calvin, W., 2010. MRO (CRISM/MARCI) Mapping of the North Pole - First Mars Year of Observations. Lunar Planet. Sci. 41. Abstract 1278.

Brown, A. J., Calvin, W., McGuire, P., Murchie, S., 2010. Compact Reconnaissance Imaging Spectrometer for Mars (CRISM) south polar mapping: First Mars year of observations. J. Geophys. Res. Planets. 115, doi:10.1029/2009JE003333.

Brown, A. J., Calvin, W., Hollingsworth, J. L., Schaefer, J. R., Michaels, T. I., Mellem, B. A., 2011. CRISM and MARCI Observations of North Polar Springtime Recession for MY 29/30. . Fifth International Conference on Mars Polar Science and Exploration Abstract 6060 . 
966 Boyce, J.M., Mouginis-Mark, P., Garbeil, H., 2005. Ancient oceans in the northern lowlands of Mars: Evidence from impact crater depth/diameter relationships. J.Geophys. Res. 110, doi:10.1029/2004JE002328.

969

Byrne, S., Dundas, C.M., Kennedy, M.R., Mellon, M.T., McEwen, A.S., Cull, S.C., Daubar, I.J., Shean, D.E., Seelos, K.D., Murchie, S.L., Cantor, B.A., Arvidson, R.E., Edgett, K.S., Reufer, A., Thomas, N., Harrison, T.N., Posiolova, L.V., Seelos, F.P., 2009. Distribution of mid-latitude ground ice on mars from new impact craters. Science 325,

Calvin, W. M., Roach, L. H., Seelos, F. P., Seelos, K. D., Green, R. O., Murchie, S. L., 975 Mustard, J. F., 2009. Compact Reconnaissance Imaging Spectrometer for Mars

976 observations of northern Martian latitudes in summer. J. Geophys. Res. 114,

977 doi:10.1029/2009JE003348.

978

Christeson, G. L., Nakamura, Y., Buffler, R. T., Morgan, J., Warner, M., 2001. Deep crustal 979 structure of the Chicxulub impact crater. J. Geophys. Res. 106 (B10), 21751-21769.

Clifford, S. M., 1993. A Model for the Hydrologic and Climatic Behavior of Water on Mars. J. 981 Geophys. Res. Planets 98 (E6), 10973-11016.

Clifford, S. M., Parker, T. J., 2001. The evolution of the Martian hydrosphere: Implications for 984 the fate of a primordial ocean and the current state of the northern plains. Icarus 154 (1), 40-79.

Clifford, S. M., Lasue, J., Heggy, E., Boisson, J., McGovern, P., Max, M. D., 2010. Depth of 986 the Martian cryosphere: Revised estimates and implications for the existence and detection of subpermafrost groundwater. J. Geophys. Res. 115 (E7), doi:10.1029/2009JE003462. 
989 Cull, S., Arvidson, R. E., Mellon, M., Wiseman, S., Clark, R., Titus, T., Morris, R. V.,

990 McGuire, P., 2010. Seasonal $\mathrm{H}_{2} \mathrm{O}$ and $\mathrm{CO}_{2}$ ice cycles at the Mars Phoenix landing

991

992

993

994

995

996

997

998

999

1000

1001

1002

1003

1004

1005

1006

1007

1008

1009

1010 site: 1. Prelanding CRISM and HiRISE observations. J. Geophys. Res. 115, doi:10.1029/2009JE003340.

Cutts, J.A., 1973.Nature and origin of layered deposits of the Martian polar regions. J. Geophys. Res., 78, 4231-4249.

El Maarry, M. R., Markiewicz, W. J., Mellon, M. T., Goetz, W., Dohm, J. M., Pack, A., 2010. Crater floor polygons: Desiccation patterns of ancient lakes on Mars? J. Geophys. Res. 115 (E10), doi:10.1029/2010JE003609.

Ewing, R. C., Peyret, A.-P. B., Kocurek, G., Bourke, M., 2010. Dune field pattern formation and recent transporting winds in the Olympia Undae Dune Field, north polar region of Mars. J. Geophys. Res. 115 (E8), doi:10.1029/2009JE003526.

Feldman, W. C., Prettyman, T. H., Maurice, S., Plaut, J. J., Bish, D. L., Vaniman, D. T., Mellon, M. T., Metzger, A. E., Squyres, S. W., Karunatillake, S., Boynton, W. V., Elphic, R. C., Funsten, H. O., Lawrence, D. J., Tokar, R. L., 2004. Global distribution of near-surface hydrogen on Mars. J. Geophys. Res. 109 (E9), doi:10.1029/2003JE002160.

Fenton, L.K., Hayward, R.K., 2010. Southern high latitude dune fields on Mars: Morphology, aeolian inactivity, and climate change. Geomorphology 121, 98-121.

Fishbaugh, K. E., Head, J. W., 2000. North polar region of Mars: Topography of circumpolar deposits from Mars Orbiter Laser Altimeter (MOLA) data and evidence for asymmetric retreat of the polar cap. J. Geophys. Res. 105, 22455-22486. 
1011 Fishbaugh, K. E., Hvidberg, C. S., 2006. Martian north polar layered deposits stratigraphy: 1012 Implications for accumulation rates and flow. J. Geophys. Res. 111 (E6), 1013 doi:10.1029/2005je002571.

1014 Garvin, J. B., Sakimoto, S. E. H., Frawley, J. J., Schnetzler, C., 2000. North Polar Region 1015 Craterforms on Mars: Geometric Characteristics from the Mars Orbiter Laser $1016 \quad$ Altimeter. Icarus 144, 329-352.

1017 Garvin, J. B., 2005. Impact Craters on Mars: Natural 3D Exploration Probes of Geological 1018 Evolution. Workshop on the Role of Volatiles and Atmospheres on Martian Impact 1019 Craters. LPI Laurel, Maryland. Abstract 1273, p.38-39.

1020 Gillespie, A. R., Montgomery, D. R., Mushkin, A., 2005. Planetary science: Are there active 1021 glaciers on Mars? Nature. 438 (7069), E9-E10.

1022 Hajigholi, M., Bertilsson, S. A. M., Brown, A. J., McKay, C. P., Fredriksson, S., 2010. 1023 Monitoring Seasonal Behavior of Ices in the Craters in the Martian Northern Polar 1024 Region with CTX and HiRISE. Lunar Planet. Sci. 41. Abstract 1553.

1025 Harrison, T. N., Malin, M. C., Edgett, K. S., Shean, D. E., Kennedy, M. R., Lipkaman, L. J., 1026 Cantor, B. A., Posiolova, L. V., 2010. Impact-induced overland fluid flow and 1027 channelized erosion at Lyot Crater, Mars. Geophys. Res. Lett. 37 (21), doi:10.1029/2010gl045074.

1029 Hartmann, W. K., Neukum, G., 2001. Cratering Chronology and the Evolution of Mars. $1030 \quad$ Space Sci. Rev. 96, 165-194.

1031 Herkenhoff, K. E., Byrne, S., Russell, P. S., Fishbaugh, K. E., McEwen, A. S., 2007. Meter1032 Scale Morphology of the North Polar Region of Mars. Science 317 (5845), 1711$1033 \quad 1715$. 
1034 Hovius, N., Conway, S. J., Barnie, T. D., Besserer, J., 2009. Ice Filled Craters in Mars' North 1035 Polar Region -- Implications for Sub-Surface Volatiles. Lunar Planet. Sci. 40. Abstract 1036 2042.

1037 Howard, A. D., 2000. The Role of Eolian Processes in Forming Surface Features of the 1038 Martian Polar Layered Deposits. Icarus 144 (2), 267-288.

1039 Ingersoll, A. P., 1970. Mars: Occurrence of liquid water. Science 168, 972-973.

1040 Ivanov, A. B., Muhleman, D. O., 2001. Cloud Reflection Observations: Results from the Mars $1041 \quad$ Orbiter Laser Altimeter. Icarus 154 (1), 190-206.

1042 Jakosky, B. M., Mellon, M. T., Varnes, E. S., Feldman, W. C., Boynton, W. V., Haberle, R. 1043 M., 2005. Mars low-latitude neutron distribution: Possible remnant near-surface water 1044

Johnson, C. L., Solomon, S. C., Head, J. W., Phillips, R. J., Smith, D. E., Zuber, M. T., 2000. Lithospheric Loading by the Northern Polar Cap on Mars. Icarus 144 (2), 313-328.

1047 Kieffer, H.H., Martin, T.Z., Peterfreund, A.R., Jakosky, B.M., Miner, E.D., Palluconi, F.D., 1048 1977. Thermal and Albedo Mapping of Mars During the Viking Primary Mission. J. 1049 Geophys. Res. 82, 4249-4291, doi:10.1029/JS082i028p04249.

1050 Kreslavsky, M. A., Head, J. W., 2006. Modification of impact craters in the northern plains of 1051 1052 Mars: Implications for Amazonian climate history. Meteorit. Planet. Sci. 41, 16331646. Region of Mars. Lunar Planet. Sci. 40. Abstract 1006. 
1055 Langevin, Y., Poulet, F., Bibring, J. P., Gondet, B., 2005. Summer evolution of the north polar cap of Mars as observed by OMEGA/Mars express. Science. 307 (5715), 15811584.

Laskar, J., Levrard, B., Mustard, J. F., 2002. Orbital forcing of the martian polar layered deposits. Nature 419 (6905), 375-377.

1060 Levrard, B., Forget, F., Montmessin, F., Laskar, J., 2004. Recent ice-rich deposits formed at high latitudes on Mars by sublimation of unstable equatorial ice during low obliquity.

Levrard, B., Forget, F., Montmessin, F., Laskar, J., 2007. Recent formation and evolution of northern Martian polar layered deposits as inferred from a Global Climate Model. J.

1065 Geophys. Res. 112 (E6), E06012.

Levy, J., Head, J. W., Marchant, D. R., 2010. Concentric crater fill in the northern midlatitudes of Mars: Formation processes and relationships to similar landforms of glacial origin. Icarus 209 (2), 390-404.

Longhi, J., 2006. Phase equilibrium in the system $\mathrm{CO}_{2}-\mathrm{H}_{2} \mathrm{O}$ : Application to Mars. J. Geophys. Res. Planets. 111 (E6), doi:10.1029/2005JE002552.

1071 Massé, M., Bourgeois, O., Le Mouélic, S., Verpoorter, C., Spiga, A., Le Deit, L., 2012. Wide distribution and glacial origin of polar gypsum on Mars. Earth Planet. Sci. Lett. 317318, 44-55.

Mellon, M. T., Arvidson, R. E., Malin, M. C., Lemmon, M. T., Heet, T., Marshall, J., Sizemore, H. G., Searls, M. L., Phoenix Science Team, 2008. The Periglacial Landscape and Ground Ice at the Mars Phoenix Landing Site. AGU Fall Meeting Abstracts 14, 08. 
Milkovich, S. M., Head, J. W., 2005. North polar cap of Mars: Polar layered deposit characterization and identification of a fundamental climate signal. J. Geophys. Res. 110 (E1), doi:10.1029/2004JE002349.

Milkovich, S. M., Head, J. W., Gerhard, N., 2008. Stratigraphic analysis of the northern polar layered deposits of Mars: Implications for recent climate history. Planet. Space Sci. 56 (2), 266-288.

Montmessin, F., Harberle, R. M., Forget, F., Langevin, Y., Clancy R. T., Bibring, J.-P. On the origin of perennial water ice at the south pole of Mars: A precession-controlled mechanism? J. Geophys. Res. Planets. 112 (E8), doi:10.1029/2007JE002902.

Moore, J.M., Mellon, M.T., Zent, A.P., 1996. Mass Wasting and Ground Collapse in Terrains of Volatile-Rich Deposits as a Solar System-Wide Geological Process: The PreGalileo View. Icarus 122, 63-78.

Morgan, F., Seelos, F., Murchie, S., CRISM Team, 2009. 'CAT Tutorial', CRISM Data Users' Workshop at Lunar Planet. Sci. 40.

Mouginot, J., Pommerol, A., Kofman, W., Beck, P., Schmitt, B., Herique, A., Grima, C., Safaeinili, A., Plaut, J. J., 2010. The 3-5 MHz global reflectivity map of Mars by MARSIS/Mars Express: Implications for the current inventory of subsurface $\mathrm{H}_{2} \mathrm{O}$. Icarus $210(2), 612-625$.

Newsom, H. E., Brittelle, G. E., Hibbitts, C. A., Crossey, L. J., Kudo, A. M., 1996. Impact crater lakes on Mars. J. Geophys. Res. 101 (E6), 14951-14955.

Osinski, G. R., Lee, P., Parnell, J., Spray, J. G., Baron, M. T., 2005. A case study of impactinduced hydrothermal activity: The Haughton impact structure, Devon Island, Canadian high arctic. Meteorit. Planet. Sci. 40 (12), 1859-1877. 
1100 Pankine, A. A., Tamppari, L. K., Smith, M. D., 2009. Water vapor variability in the north polar 1101 region of Mars from Viking MAWD and MGS TES datasets. Icarus 204 (1), 87-102.

1102 Perron, J. T., Mitrovica, J. X., Manga, M., Matsuyama, I., Richards, M. A., 2007. Evidence of 1103 an ancient martian ocean in the topography of deformed shorelines. Nature 447, 840$1104 \quad 843$.

1105 Perron, J. T., Huybers, P., 2009. Is there an orbital signal in the polar layered deposits on Mars? Geology 37 (2), 155-158.

1107 Phillips, R. J., Zuber, M. T., Smrekar, S. E., Mellon, M. T., Head, J. W., Tanaka, K. L., Putzig, N. E., Milkovich, S. M., Campbell, B. A., Plaut, J. J., Safaeinili, A., Seu, R., Biccari, D., Carter, L. M., Picardi, G., Orosei, R., Surdas Mohit, P., Heggy, E., Zurek,

1113 Plaut, J. J., Safaeinili, A., Holt, J. W., Phillips, R. J., Head, J. W., Seu, R., Putzig, N. E., Frigeri, A., 2009. Radar evidence for ice in lobate debris aprons in the mid-northern latitudes of Mars. Geophys. Res. Lett. 36, 02203.

1116 Putzig, N. E., Phillips, R. J., Campbell, B. A., Holt, J. W., Plaut, J. J., Carter, L. M., Egan, A. F., Bernardini, F., Safaeinili, A., Seu, R., 2009. Subsurface structure of Planum Boreum from Mars Reconnaissance Orbiter Shallow Radar soundings. Icarus 204

1120 Rathbun, J. A., Squyres, S. W., 2002. Hydrothermal Systems Associated with Martian Impact Craters. Icarus 157, 362-372. 
1122 Rodríguez, J. A. P., Tanaka, K. L., Berman, D. C., Kargel, J. S., 2010. Late Hesperian plains 1123 formation and degradation in a low sedimentation zone of the northern lowlands of $1124 \quad$ Mars. Icarus $210(1), 116-134$.

1125 Russell, P. S., Head, J. W., 2002. The martian hydrosphere/cryosphere system: Implications of the absence of hydrologic activity at Lyot crater. Geophys. Res. Lett. 29 (17), doi:10.1029/2002GL015178.

Russell, P. S., Head, J. W., Hecht, M. H., 2003. Evolution of Volatile-rich Crater Interior Deposits on Mars. Sixth International Conference on Mars. Abstract 3256.

1130 Russell, P. S., J. W. Head, I., Hecht, M. H., 2004. Evolution of Ice Deposits in the Local Environment of Martian Circum-Polar Craters and Implications for Polar Cap History.

1133 Russo, F., Cutigni, M., Orosei, R., Taddei, C., Seu, R., Biccari, D., Giacomoni, E., Fuga, O., Flamini, E., 2008. An incoherent simulator for the SHARAD experiment. Radar

Sakimoto, S. E. H., 2005. Central Mounds in Martian Impact Craters: Assessment as Possible Perennial Permafrost Mounds (Pingos). Lunar Planet. Sci. 36. Abstract

Seelos, K. D., Seelos, F. P., Titus, T. N., Murchie, S. L., Crism, T., 2008. CRISM Conference, RADAR '08. IEEE, Rome, Italy, doi:10.1109/RADAR.2008.4720761

Selvans, M. M., Plaut, J. J., Aharonson, O., Safaeinili, A., 2010. Internal structure of Planum Boreum, from Mars advanced radar for subsurface and ionospheric sounding data. J. Geophys. Res. 115 (E9), doi:10.1029/2009JE003537. 
1145 Smith, D. E., Zuber, M. T., Neumann, G. A., 2001. Seasonal Variations of Snow Depth on $1146 \quad$ Mars. Science 294 (5549), 2141-2146.

1147 Smith, I. B., Holt, J. W., 2010. Onset and migration of spiral troughs on Mars revealed by $1148 \quad$ orbital radar. Nature 465 (7297), 450-453.

1149 Spiga, A., Forget, F., Madeleine, J.-B., Montabone, L., Lewis, S.R., Millour, E., 2011. The 1150 impact of martian mesoscale winds on surface temperature and on the determination $1151 \quad$ of thermal inertia. Icarus $212,504-519$.

1152 Stepinski, T. F., Mendenhall, M. P., Bue, B. D., 2009. Machine cataloging of impact craters on Mars. Icarus 203 (1), 77-87.

1154 Tanaka, K. L., Skinner Jr, J. A., Hare, T. M., 2005. Geologic map of the northern plains of Mars. Scientific Investigation Map 2888. USGS/NASA.

1156 Tanaka, K. L., Hayward, R. K., 2008. Mars' North Circum-Polar Dunes: Distribution, Sources, and Migration History. Planetary Dunes Workshop: A Record of Climate Change, held April 29-May 2, 2008 in Alamogordo, New Mexico. Abstract1403, p.69-

1160 Tanaka, K. L., Rodriguez, J. A. P., Skinner Jr, J. A., Bourke, M. C., Fortezzo, C. M., 1161 Herkenhoff, K. E., Kolb, E. J., Okubo, C. H., 2008. North polar region of Mars: Advances in stratigraphy, structure, and erosional modification. Icarus 196 (2), 318-

1164 Titus, T.N., Kieffer, H.H., Mullins, K.F., Christensen, P.R., 2001. TES premapping data: Slab ice and snow flurries in the Martian north polar night. J. Geophys. Res. 106, 2318123196, doi : 10.1029/2000JE001284.

1167 Vincendon, M., 2008. Modélisation du transfert radiatif dans l'atmosphère martienne pour la détermination des propriétés spectrales de surface et la caractérisation des aérosols 

martiens à partir des données OMEGA. PhD Thesis, Université de Paris-Sud XI, pp. 193.

1171 Vincendon, M., Langevin, Y., Poulet, F., Bibring, J. P., Gondet, B., Schmitt, B., Douté, S., 1172 2006. Surface Water Ice and Aerosols Evolution of $77^{\circ} \mathrm{N}, 90^{\circ} \mathrm{E}$ Mars Crater During 1173 Early Summer by OMEGA/MEx. Lunar Planet. Sci. 37. Abstract 1769.

1174 Vincendon, M., Forget, F., Mustard, J., 2010. Water ice at low to midlatitudes on Mars. J. 1175 Geophys. Res. 115, doi:10.1029/2010JE003584.

1176 Wagstaff, K. L., Titus, T. N., Ivanov, A. B., Castaño, R., Bandfield, J. L., 2008. Observations 1177 of the north polar water ice annulus on Mars using THEMIS and TES. Planet. Space 1178 Sci. $56(2), 256-265$.

1179 Westbrook, O.W., 2009. Crater ice deposits near the south pole of Mars. Masters Thesis, $1180 \quad$ Massachusetts Institute of Technology, pp. 60. 


\section{Figure Captions}

1183 Figure 1: Depth-diameter plot of all the craters north of $65^{\circ} \mathrm{N}$, with ice-filled craters and dune-

1184 filled craters highlighted. Lines extending above the mound-points are the predicted depths

1185 of the craters with the mounds removed. Depth-diameter relationship derived for polar

1186 craters by Garvin et al. (2000) and the general relationship for Martian craters (Garvin, 2005)

1187 are marked. An anomalous pixel in the MOLA data has resulted in a $\sim 1.5 \mathrm{~km}$ crater with

$1188>1 \mathrm{~km}$ depth, we believe this pixel to be an error in the data; hence this point should be

1189 ignored.

1190

1191 Figure 2: Map of the north polar region of Mars made from MOLA topography with overlain

1192 hillshade. It includes the locations of the mounds studied and locations of the swaths used to

1193 produce Fig. 4. Outlined in grey are all the craters included in the survey. The "+" indicates

1194 the position of crater 332, which is mentioned in the text, but does not have a significant

1195 mound. "OM" indicates the position of Fig. 17, with the arrow showing the viewing direction.

1196 "Complete dune cover" means that the mound spans the whole crater floor and is covered in

1197 dunes and "dune-covered mounds" are those which are covered in dunes, but only occupy

1198 part of the crater floor (the rest of the crater floor is dune-free.)

1199

1200 Figure 3: Left, Crater 388 Dokka. Perspective view (with 3x vertical exaggeration) of a

1201 subset of HRSC nadir (RGB-color online) image H1177_0000 draped over MOLA

1202 topography with profiles A-A' and B-B' marked and shown beneath. Right: Crater 811.

1203 Perspective view (with 3x vertical exaggeration) of a subset of HRSC nadir (RGB-color

1204 online) image H3711_0000 draped over MOLA topography with profiles C-C' and D-D'

1205 marked. The $20 \mathrm{~m}$ scale vertical roughness on profiles $C$ and $D$ is a result of the overlying

1206 dunes. Arrow points to North in both figures. Profiles A, B, C and D were generated from 
1207 MOLA topography - note the exaggeration of the vertical scale. Credit for HRSC images

1208 ESA/DLR/FU Berlin (G. Neukum).

1209

1210 Figure 4: Histogram plots of the elevation variation with latitude within the swaths outlined in

1211 Fig. 2. Black (blue online) indicates craters with ice-mounds and the height to which those

1212 mounds reach, labels correspond to those in Fig. 2 and Table 1. Note that the vertical scale

1213 is exaggerated.

1214

1215 Figure 5: Bar chart of calculated mound volume for each crater in descending order. Note

1216 the logarithmic scale on the $y$-axis. The mean value $\left(314.7 \mathrm{~km}^{3}\right)$ is indicated by the upper

1217 dashed line and the median value $\left(17.01 \mathrm{~km}^{3}\right)$ by the lower dotted line.

1218

1219 Figure 6: Right optical image with scale and north arrow, and left optical image overlain by

1220 proportion of water ice detected (band depth at $1.5 \mu \mathrm{m}$ ).

1221 (A) Korolev crater (206), optical images from MRO CTX P20_008831_2529_XN_72N195W

$1222\left(L_{s} 85.33^{\circ}\right), P 21 \_009042 \_2528 \_X I \_72 N 197 W\left(L_{s} 92.58^{\circ}\right)$,

1223 P21_009332_2529_XN_72N194W (L $\left.L_{s} 102.66^{\circ}\right), P 22 \_009477 \_2530 \_X N \_73 N 193 W\left(L_{s}\right.$ 1224 107.77 $),$ P22_009754_2529_XN_72N195W $\left(\mathrm{L}_{\mathrm{s}} 117.69^{\circ}\right)$, and OMEGA track 0987_2 $\left(\mathrm{L}_{\mathrm{s}}\right.$ $\left.1225105.9^{\circ}\right)$

1226 (B) Dokka crater (388), optical images MRO CTX B01_010108_2573_XN_77N144W (Ls $\left.1227130.74^{\circ}\right)$ and B02_010385_2572_XN_77N146W $\left(L_{s} 141.32^{\circ}\right)$, OMEGA track 1221_1 $\left(L_{s}\right.$ $\left.1228 \quad 136.4^{\circ}\right)$

1229 (C) Crater 544, optical images THEMIS V13697003 ( $\left.L_{s} 144.508\right)$ and V12474005 $\left(L_{s}\right.$

$\left.123097.106^{\circ}\right)$, OMEGA track $1257 \_0\left(L_{s} 141.3^{\circ}\right)$.

1231 (D) Crater 579, optical image MRO CTX P02_001819_2570_XN_77N270W $\left(L_{s} 151.16^{\circ}\right)$, 1232 OMEGA track 1017_1 $\left(L_{s} 109.5^{\circ}\right)$. 
1233 (E) Louth crater (503), optical image HRSC h1343_0001 ( $\left.L_{s} 153.5^{\circ}\right)$, OMEGA track 1017_1

$1234\left(\mathrm{~L}_{s} 109.5^{\circ}\right)$. Credit for CTX images NASA/JPL/MSSS, for HiRISE images

1235 NASA/JPL/University of Arizona, for THEMIS images NASA/JPL/ASU, for HRSC images

1236 ESA/DLR/FU Berlin (G. Neukum), for OMEGA data ESA/OMEGA.

1237

1238 Figure 7: Maps of layer exposures and measured layer dips in Korolev (206), Dokka (338),

1239 crater 579, Louth (503), crater 769 and crater 663. Shaded areas represent areas where

1240 layers were observed to be cropping out, dotted lines are selected layers to illustrate the

1241 nature of the layering and the dip and strike labels are in units of degrees. Dotted box in

1242 panel 579 indicates the approximate location of Fig. 10. Images all MRO CTX: 206 Korolev:

1243 P20_008831_2529_XN_72N195W, P21_009042_2528_XI_72N197W,

1244 P21_009332_2529_XN_72N194W, P22_009477_2530_XN_73N193W,

1245 P22_009754_2529_XN_72N195W, 388 Dokka: B01_010108_2573_XN_77N144W and

1246 B01_010108_2573_XN_77N144W, 579: P02_001819_2570_XN_77N270W, 503 Louth:

1247 P01_001370_2503_XI_70N257W, 769: B02_010407_2587_XN_78N028W, 663:

1248 P20_008795_2592_XN_79N299W. Image credit NASA/JPL/MSSS.

1249

1250 Figure 8: Boxplots of the estimated layer spacing in mounds and polar deposits. The vertical 1251 bars are the median values, the boxes delimit the interquartile range, the whiskers the range

1252 and the dots are the outliers (data points outside 1.5 interquartile ranges from the box). In

1253 grey are measurements made outside craters. Shorthand labels are as follows: 206 Korolev

1254 - layers measured in Korolev crater in CTX images P20_008831_2529_XN_72N195W and

1255 P21_009042_2528_XI_72N197W, 388 Dokka - layers measured in Dokka crater in CTX

1256 images B01_010108_2573_XN_77N144W and B02_010385_2572_XN_77N146W, 503

1257 Louth HR - layers proximal to dunes in Louth crater measured in HiRISE

1258 PSP_001700_2505, 503 Louth CTX - layers measured in CTX image

1259 P01_001370_2503_XI_70N257W at the edge of the mound in Louth, 579: layers identified in 
crater 579 in HiRISE image PSP_008926_2575, 663 - layers measured in crater 663

1261 corrected for layer dip as well as exposure slope, in HiRISE image ESP_016087_2595, 769

1262 - layers measured in crater 769 in HiRISE image PSP_008416_2585, PLD1 - layers

1263 measured in the PLD in HiRISE image PSP_010366_2590, PLD2 - layers measured in the

1264 polar layer deposits in HiRISE image TRA_000825_2665 and PLD3 - layers measured in the

1265 polar layer deposits in HiRISE image TRA_000863_2640, upper quartile is at $15.0 \mathrm{~m}$ and the

1266 upper whisker at $29.3 \mathrm{~m}$, with one outlier at $39.8 \mathrm{~m}$. BU - layers measured in the polar basal

1267 deposits in HiRISE image TRA_000863_2640.

Figure 9: Histogram of mound slopes on layer exposure sites (as shown in Fig.7) as derived from $128 \mathrm{pixel} /$ degree MOLA data. The mean of the distribution is $4.4^{\circ}$ with a standard deviation of $3.6^{\circ}$ and skew of 1.29 .

1272

1273 Figure 10: Detailed sketch (left) cross section (top right) and detail-inset (bottom-right) of the 1274 layer stratigraphy in crater 579. On the sketch dotted lines are selected layers to illustrate 1275 the nature of the layering, bold lines are the locations of unconformities and dip and strike symbol labels are in units of degrees. The line labeled I-II indicates the position of the cross section adjacent to the image. Colored lines are contours in $25 \mathrm{~m}$ intervals derived from

1278 gridded MOLA 128 pixel/degree data (see online for color version). The crater wall is located

1279 to the right in both the sketch and the cross-section. Overlain on the sketch is the CTX 1280 image P02_001819_2570_XN_77N270W, credit NASA/JPL/MSSS. Labels A, B and C are 1281 packets of layers separated by unconformities. On the cross-section dotted lines show the 1282 estimated position of the unconformities and the relative vertical positions of the three layer 1283 packets $A, B$ and $C$. From layer cross-cutting relationships we know that $A$ is older than $B$, 1284 which is older than C; hence the packets were laid down in an upwards younging sequence. 1285 The location of the inset is indicated by the grey box. The image in the inset is HiRISE image 1286 PSP_008926_2575; credit NASA/JPL/University of Arizona. 
1288 Figure 11: Depth-corrected SHARAD radargram r_0554201_001 and clutter simulation for 1289 Korolev (206) crater. South is to the right.

1290

1291 Figure 12: Map of the mound center-of-mass offsets with respect to the crater center

1292 (normalized by crater diameter) with the mapped location of north pole dunefields and wind 1293 vectors from dune slipface measurements taken from Tanaka and Hayward (2008). The

1294 vector linking the center of mass of the ice mound to the centroid of the crater rim polygon 1295 we use as a representation of the asymmetry of the mounds. Dune density is given as the 1296 relative density parameter calculated by Tanaka and Hayward (2008) as the ratio of mean 1297 dune length vs. dune crest separation.

1298

1299 Figure 13: The variation of bolometric brightness temperature with season $\left(L_{s}\right)$, inside and on

1300 the ice-free plains outside two example craters as derived from TES data downloaded using

1301 the TES Data Tool - http://tes.asu.edu/data_tool/ for Mars years 24 to 28 . The dataset

1302 contains both data collected at 2pm and 2am local solar time; hence there are two distinct

1303 temperatures between $90-180^{\circ} \mathrm{L}_{\mathrm{s}}$ when the sun is above the horizon at $2 \mathrm{pm}$. Dokka Crater

1304 (388), a $51 \mathrm{~km}$ diameter crater which contains a dome of water ice, which suppresses the

1305 temperature almost all year round relative to that outside the crater. Crater 1065 , at $70^{\circ} \mathrm{N}$,

$1306352^{\circ} \mathrm{E}$ diameter $\sim 40 \mathrm{~km}$, which has lower temperatures than the exterior only between $\mathrm{L}_{\mathrm{s}}$

$1307250^{\circ}$ and $L_{s} 320^{\circ}$. The grey band indicates the water frost point temperatures corresponding

1308 to an atmospheric water content of between 10 and 60 pr $\mu \mathrm{m}$ (Pankine et al., 2009).

1310 Figure 14: Location of temporary ice deposits which remain after the seasonal cap has 1311 retreated, as indicated by arrows. The background is a MOLA hillshade image. A: Deposits 1312 around crater 561 at $267^{\circ} \mathrm{E}, 70^{\circ} \mathrm{N}$ form a plume extending to the east, matching dominant 1313 wind directions in this area (Fig. 12).CTX images P17_007799_2513_XN_71N093W and 
1314 P18_007944_2506_XN_70N092W. B: Deposits around crater 263 at $146^{\circ} \mathrm{E}, 72^{\circ} \mathrm{N}$ are

1315 located mainly on north-facing slopes, CTX image B01_009847_2522_XN_72N214W.

1316 Image credit MSSS/NASA/JPL.

1317

1318 Figure 15: Schematic diagram of the initiation and growth of ice domes, with the ices

1319 throughout as labeled in the first panel. North is to the right in all diagrams. The thickness of

1320 the frost and ice deposits are greatly exaggerated for illustration purposes. 1. In winter the

1321 microclimate in the crater provokes additional deposition of $\mathrm{CO}_{2}$ and water ice inside the

1322 crater. 2. During the springtime sublimation, the $\mathrm{CO}_{2}$ layer inside the crater remains

1323 (because a thicker layer takes longer to sublime), while the crater exterior is denuded of $\mathrm{CO}_{2}$

1324 and the $\mathrm{H}_{2} \mathrm{O}$ starts to sublime. The $\mathrm{H}_{2} \mathrm{O}$ released from the plains around the crater can be

1325 re-deposited in the crater interior, because of its lower temperature (as the $\mathrm{CO}_{2}$ remains).3.

1326 Once the $\mathrm{CO}_{2}$ has completely sublimed, relatively thick deposits of $\mathrm{H}_{2} \mathrm{O}$ remain in the crater

$1327\left(\mathrm{H}_{2} \mathrm{O}\right.$ from winter plus the $\mathrm{H}_{2} \mathrm{O}$ re-condensed onto the $\left.\mathrm{CO}_{2}\right)$, which act as a cold trap for $\mathrm{H}_{2} \mathrm{O}$

1328 subliming outside the crater. In addition the higher atmospheric pressure inside the crater

1329 reduces the rate of sublimation of this water ice. 4. The additional thickness and the reduced

1330 sublimation enable the survival of at least several meters thick deposit of water ice through

1331 the summer, which then builds up each year. A perennial deposit creates a positive

1332 feedback whereby higher thermal inertia and higher albedo than the surrounding landscape

1333 promotes continued deposition of water ice.

1335 Figure 16: Perspective view of polar outliers near Olympia Mensae at $96.5^{\circ} \mathrm{E}, 74^{\circ} \mathrm{N}$. Vertical 1336 exaggeration is five times. Outcrop in foreground is $\sim 350 \mathrm{~m}$ tall and $10 \mathrm{~km}$ wide at the base.

1337 CTX images P21_009295_2550_XN_75N263W and P20_009018_2543_XI_74N262W used 1338 for topographic drape. Background hillshade and topography from the MOLA gridded 256 1339 tile. CTX image credit MSSS/NASA/JPL. 


\section{Supp. Mat. Figure Captions}

1342 Figure S1: MOLA hillshade image and cross sections for all 18 craters with mounds. The

1343 black line on the image corresponds to the black north-south cross section on the plot,

1344 where "N" on the image indicates the northern end. The red line indicates the position of red

1345 east-west cross section on the plot (always oriented E-W apart from for crater 503, Louth).

1346 Data from the 256 pix/deg MOLA gridded data were used to produce the hillshade and cross

1347 sections for craters $206,503,579,811,814,882,904$ and 934 ; for the others the data are

1348 derived from the 512 pix/deg gridded data. 
1349 Table 1: Summary of the characteristics of the mounds and their host craters. ${ }^{\text {a }}$

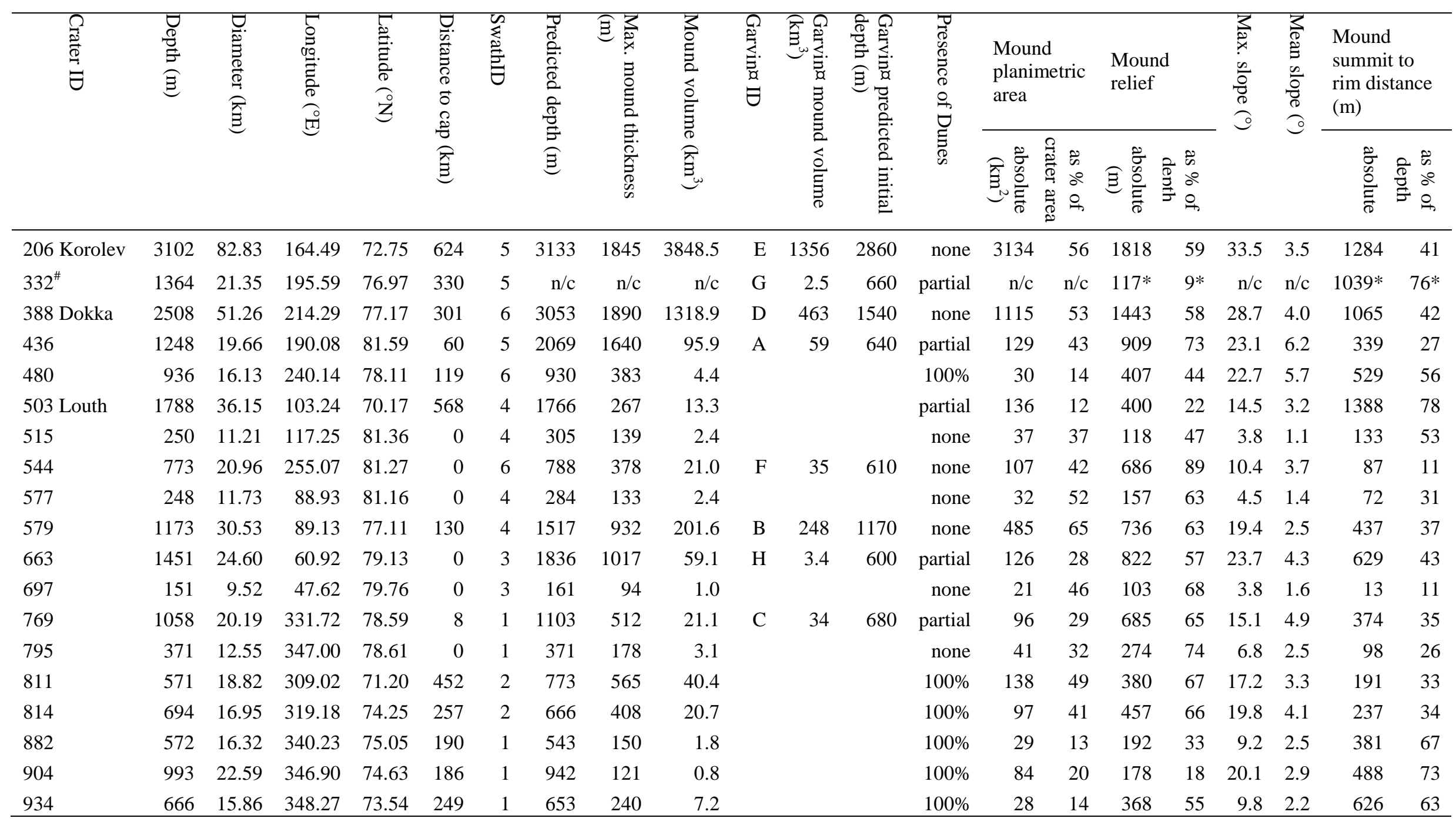




\begin{tabular}{|c|c|c|c|c|c|c|c|c|c|c|c|c|c|c|c|}
\hline Min. & 151 & 9.52 & 70.17 & 0 & 161 & 94 & 0.8 & 21 & 12 & 103 & 9 & 3.8 & 1.1 & 13 & 11 \\
\hline Mean & 1048 & 24.33 & 76.97 & 183 & 1161 & 605 & 314.7 & 326 & 36 & 563 & 54 & 15.9 & 3.3 & 495 & 44 \\
\hline Median & 936 & 19.24 & 77.17 & 130 & 859 & 381 & 17.0 & 96 & 39 & 403 & 59 & 16.2 & 3.2 & 381 & 41 \\
\hline Max. & 3102 & 82.83 & 81.59 & 624 & 3133 & 1890 & 3848.5 & 3134 & 65 & 1818 & 89 & 33.5 & 6.2 & 1388 & 78 \\
\hline
\end{tabular}

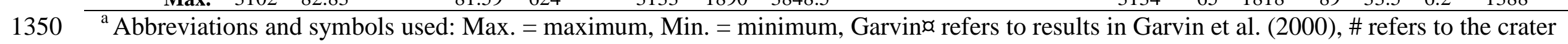

1351 that has layered deposits, but no significant mound, n/c = not calculated, and $*$ indicates that the relief was estimated from a MOLA cross

1352 profile, rather than taking the difference between the max. and min. MOLA elevations found within the mound polygon. 
Highlights:

- 18 potentially ice-cored mounds were found in craters in Mars' north polar region.

- The stratigraphy of the mounds argues for deposition from the atmosphere.

- We argue many of them were deposited separately from the polar cap.

- The crater micro-environment is a potential explanation for mound initiation.

- These mounds are sensitive and important records of Amazonian climate on Mars. 


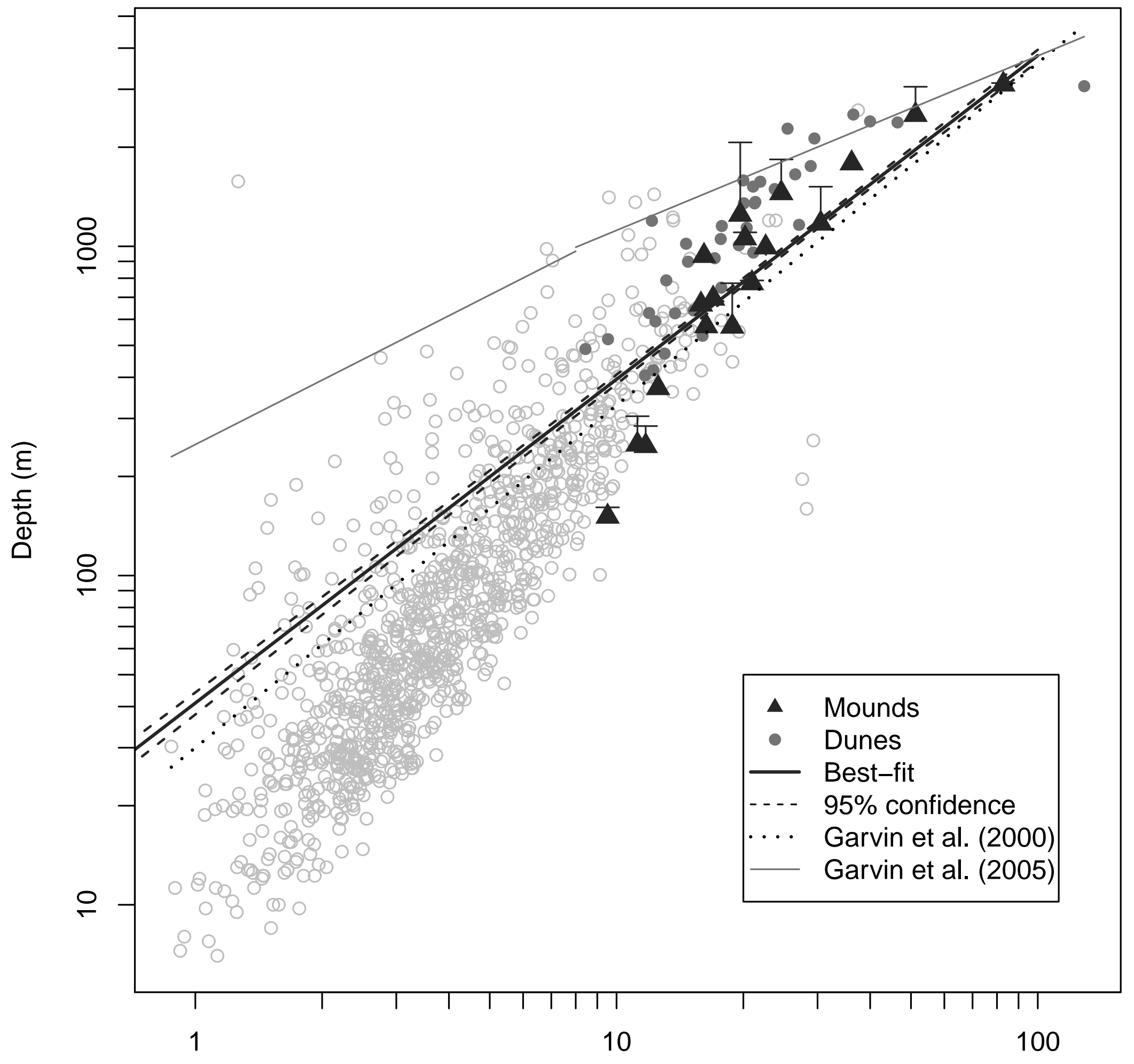

Diameter $(\mathrm{km})$ 


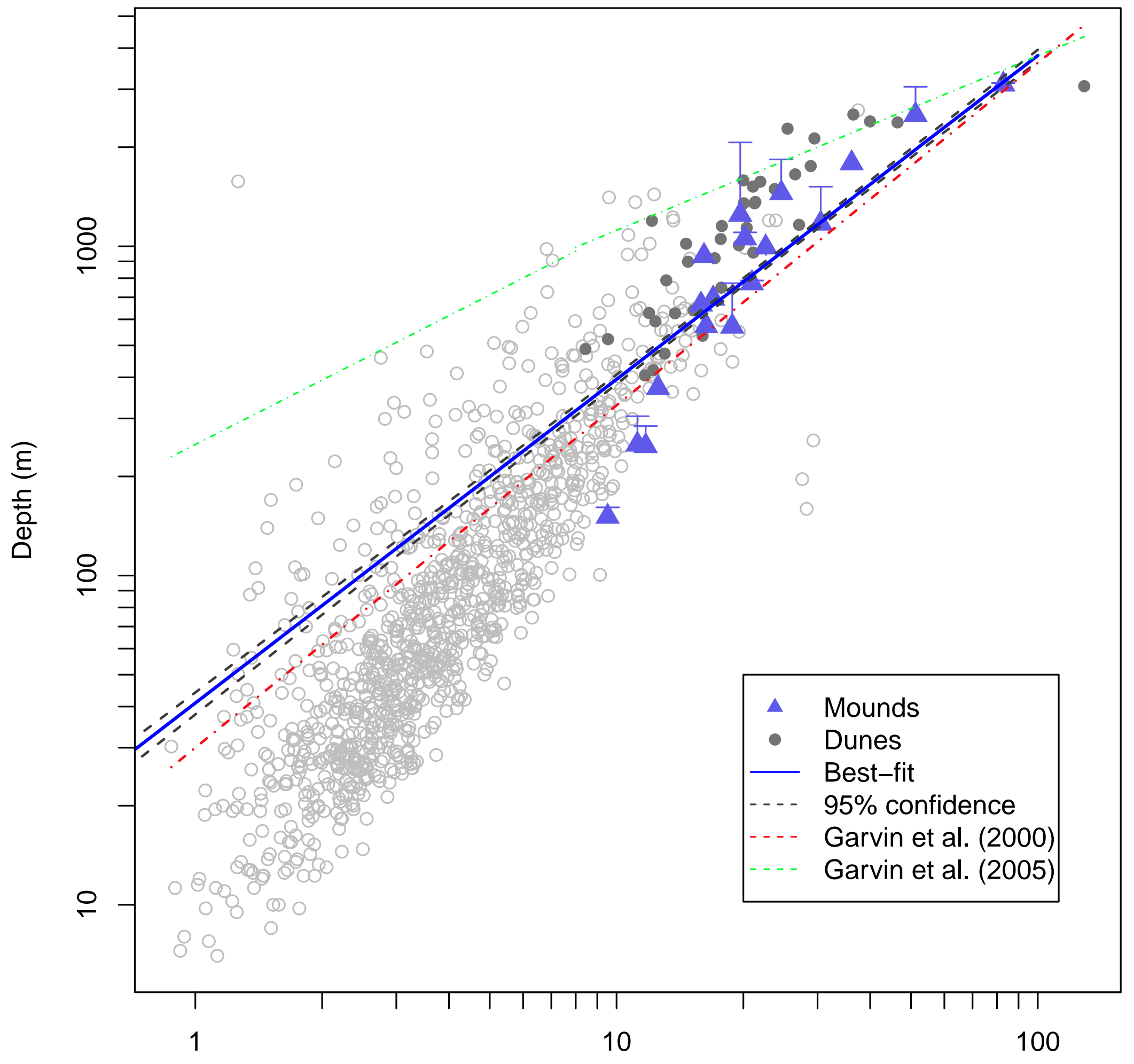

Diameter $(\mathrm{km})$ 


\section{Figure 2 (black and white)}

Click here to download high resolution image

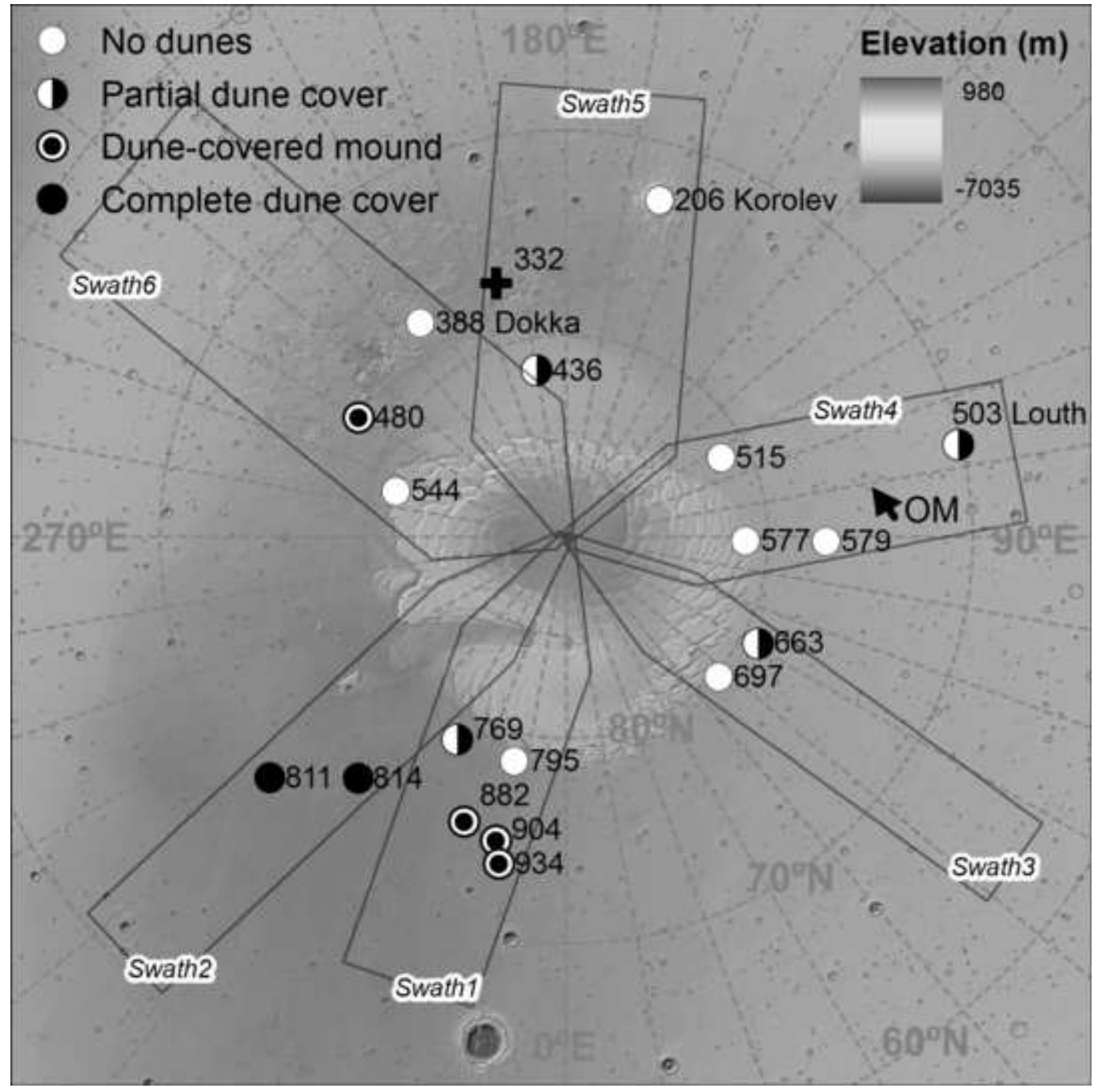


- No dunes

$180^{\circ} \mathrm{g}$

Elevation (m)

- Partial dune cover

( D Dune-covered mound

- Complete dune cover

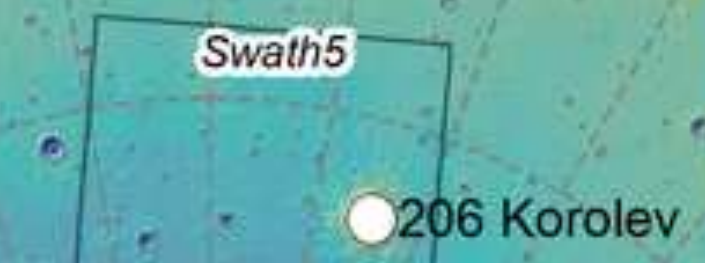

980

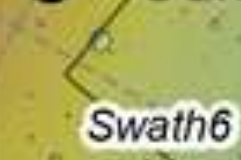

n

Swath 6

$\therefore 480$

054

388 Dokka

$270^{\circ} \mathrm{E}^{\circ}$

Swath2

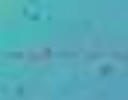

(169

436

332

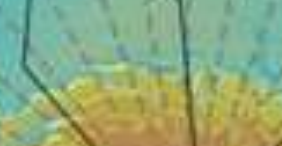

515

$577 \bigcirc 579$

rOM

$-7035$

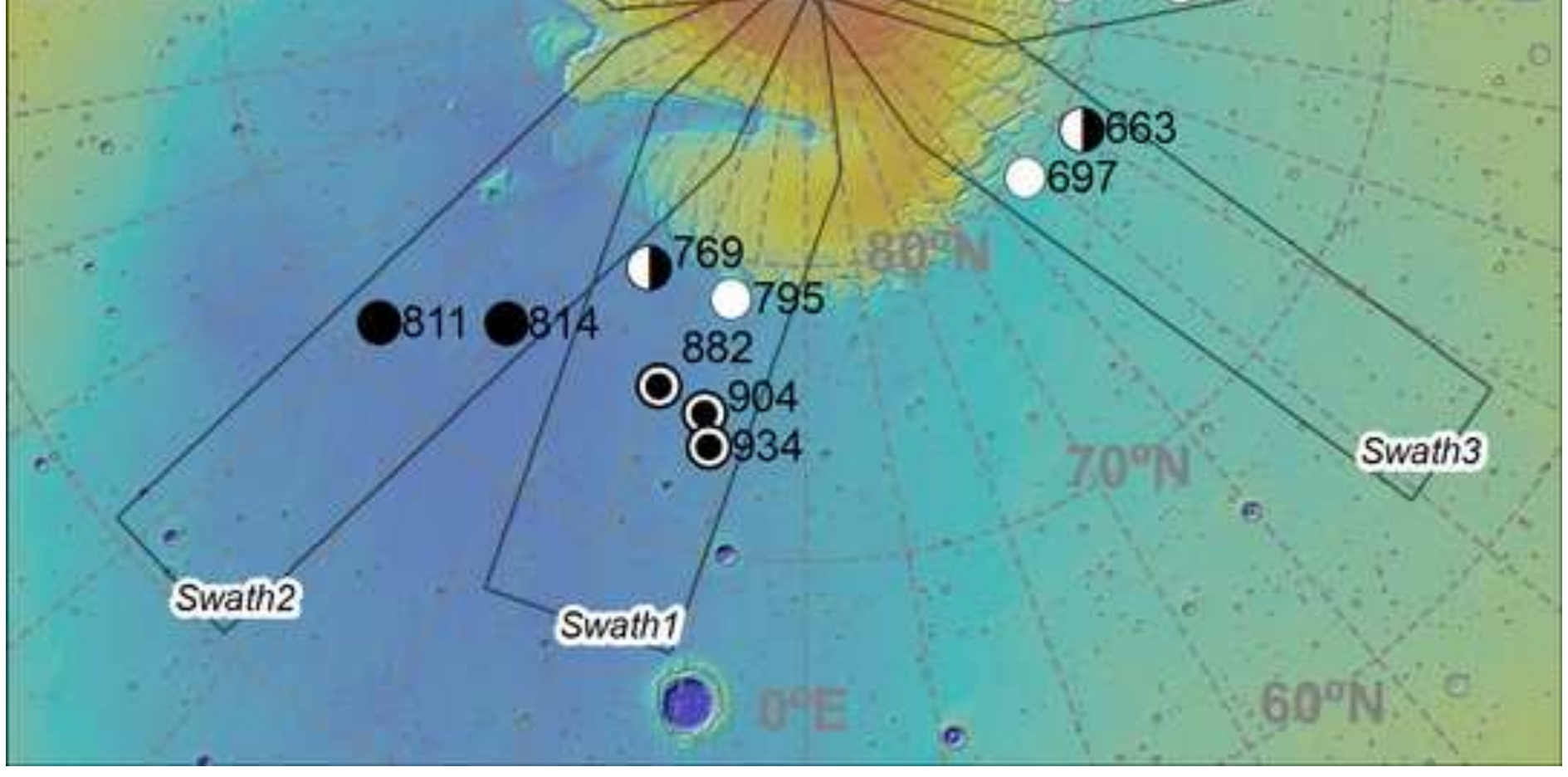



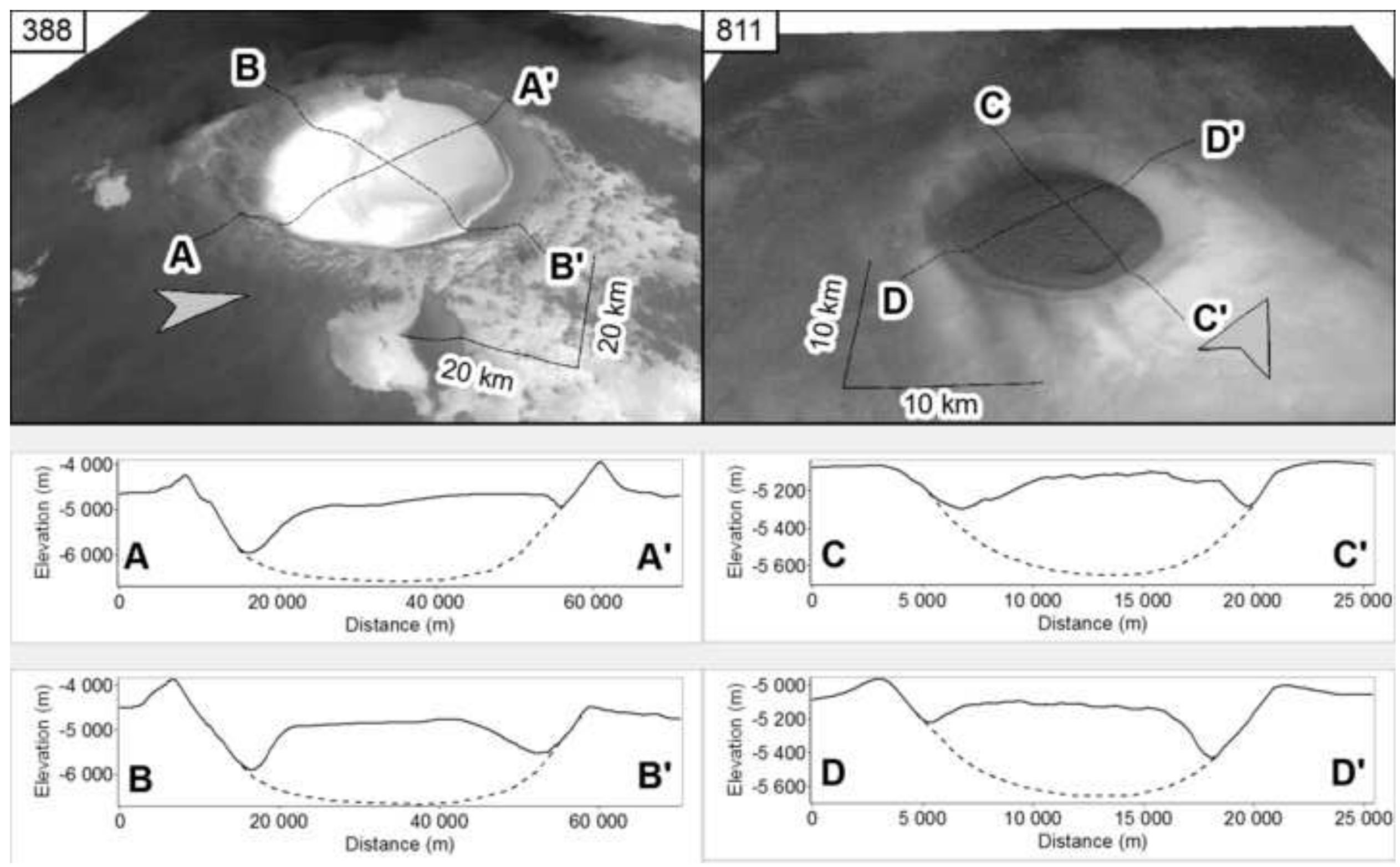
Click here to download high resolution image
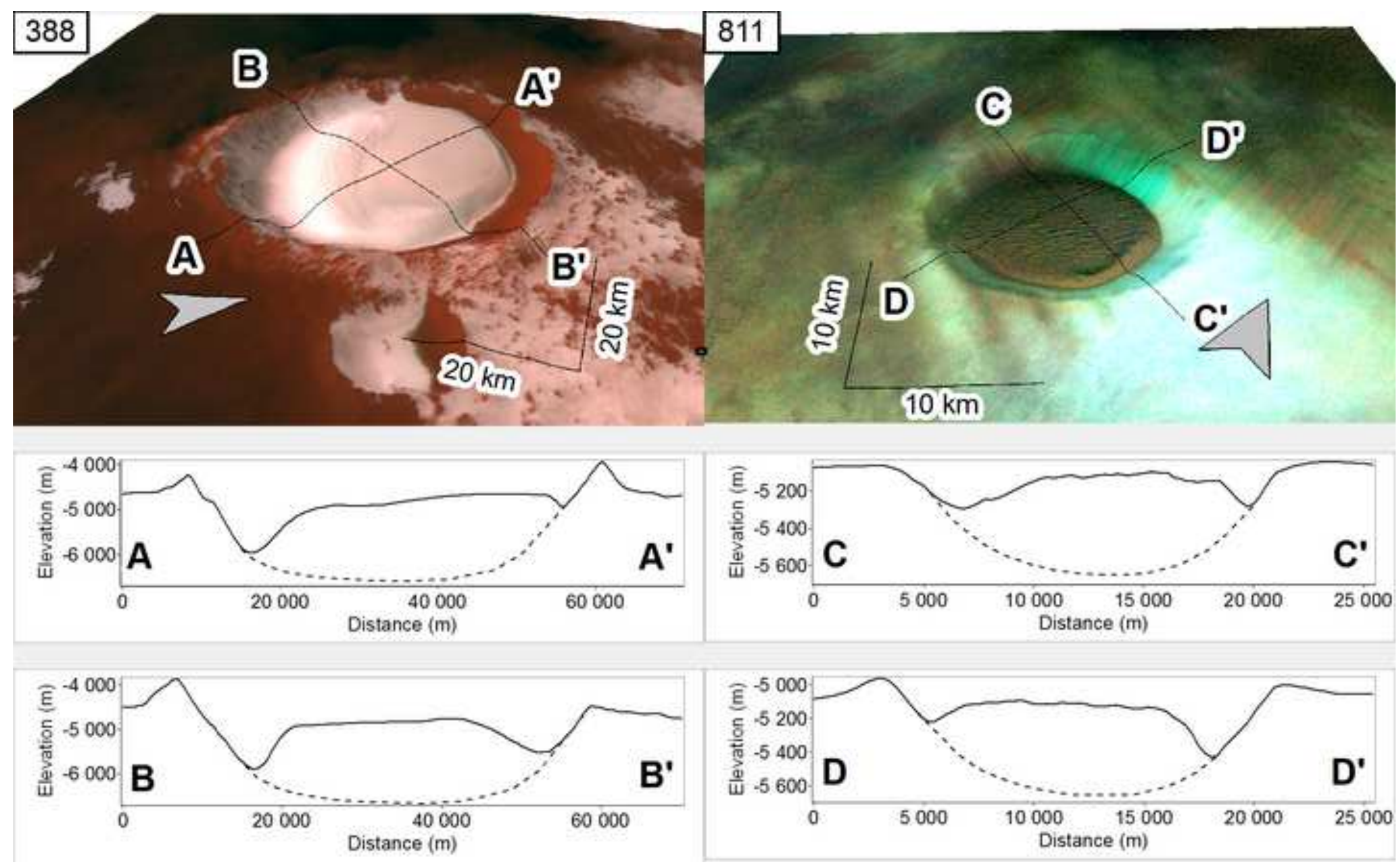


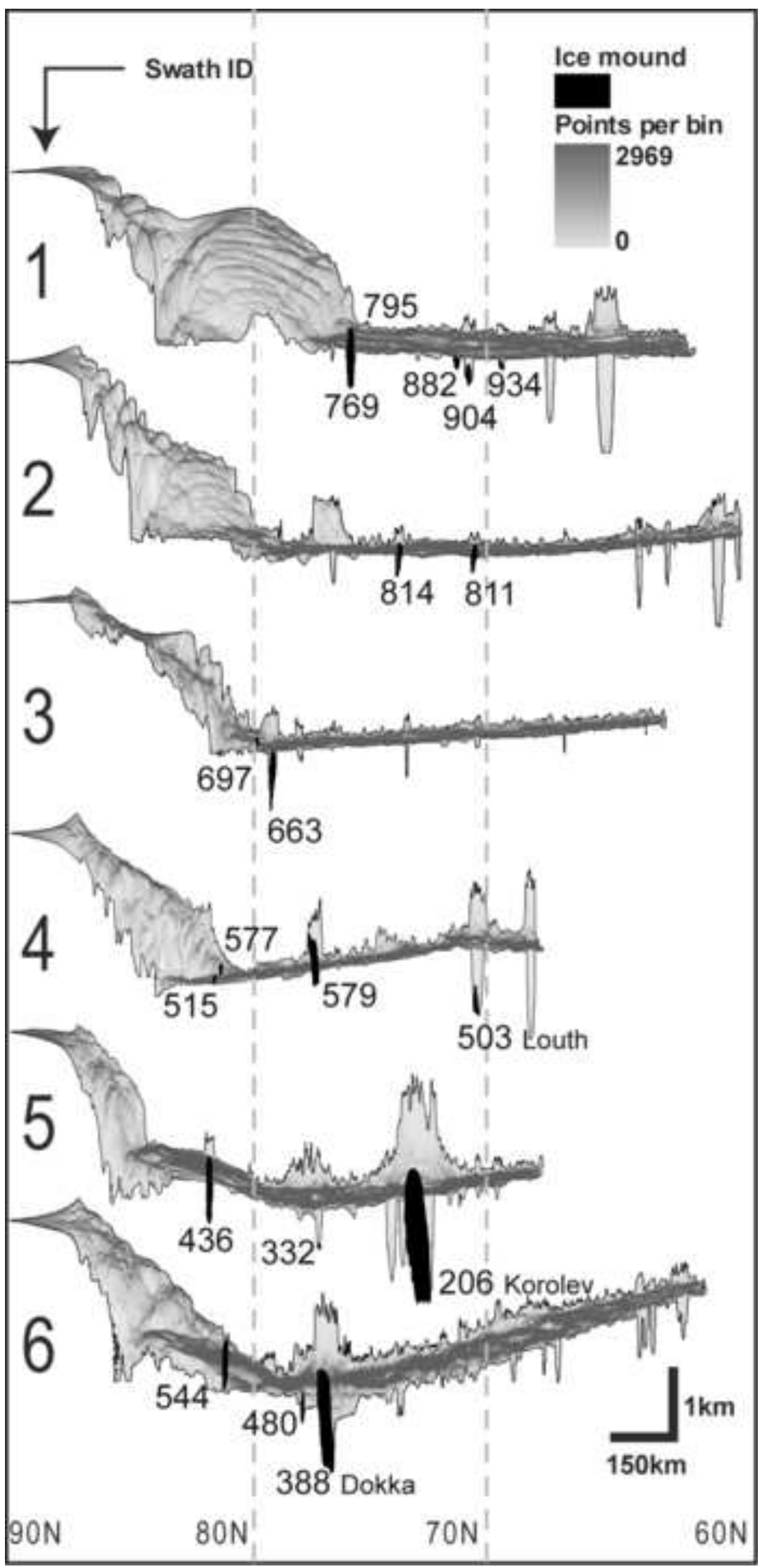


Figure 4

Click here to download high resolution image

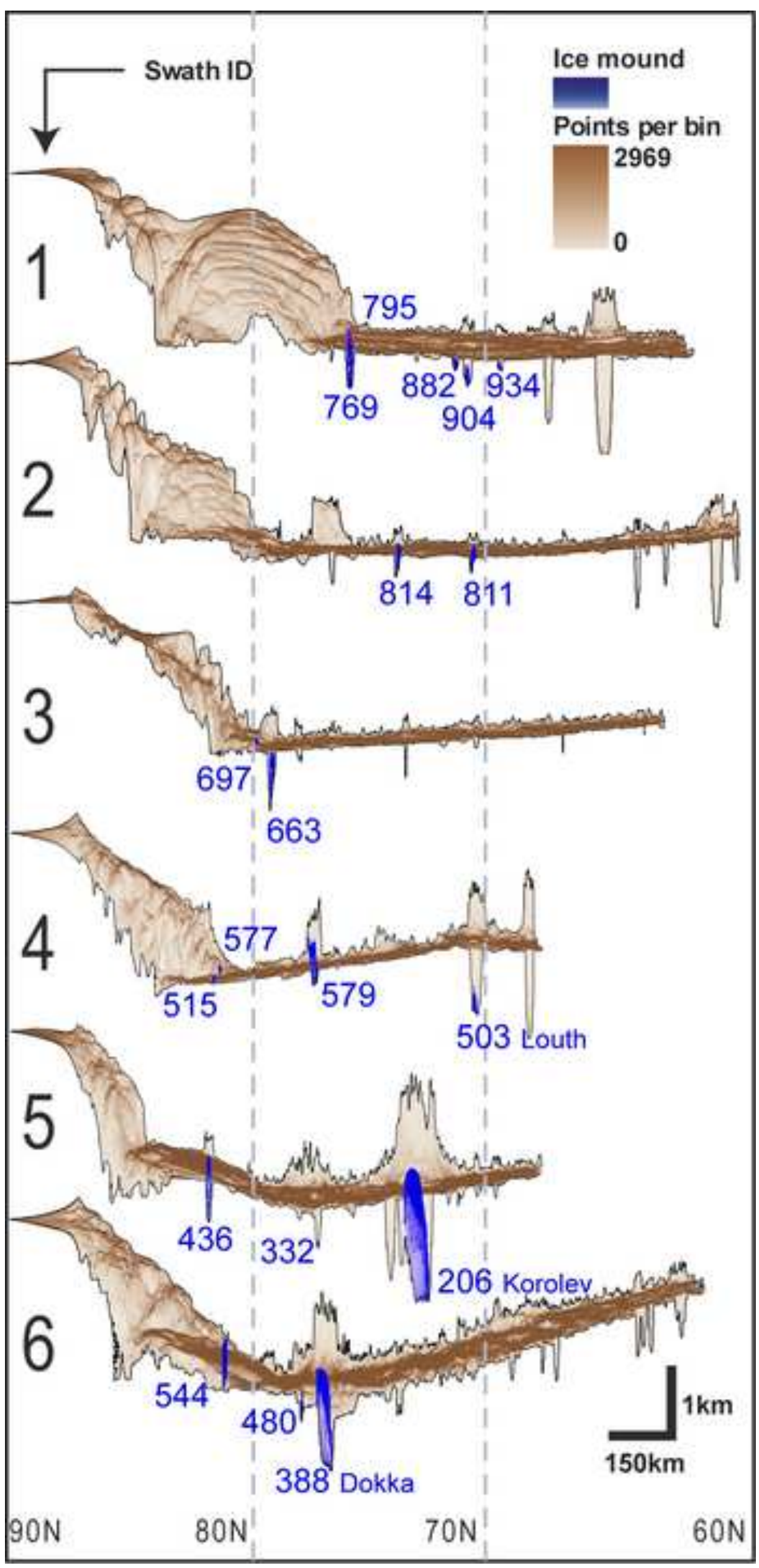




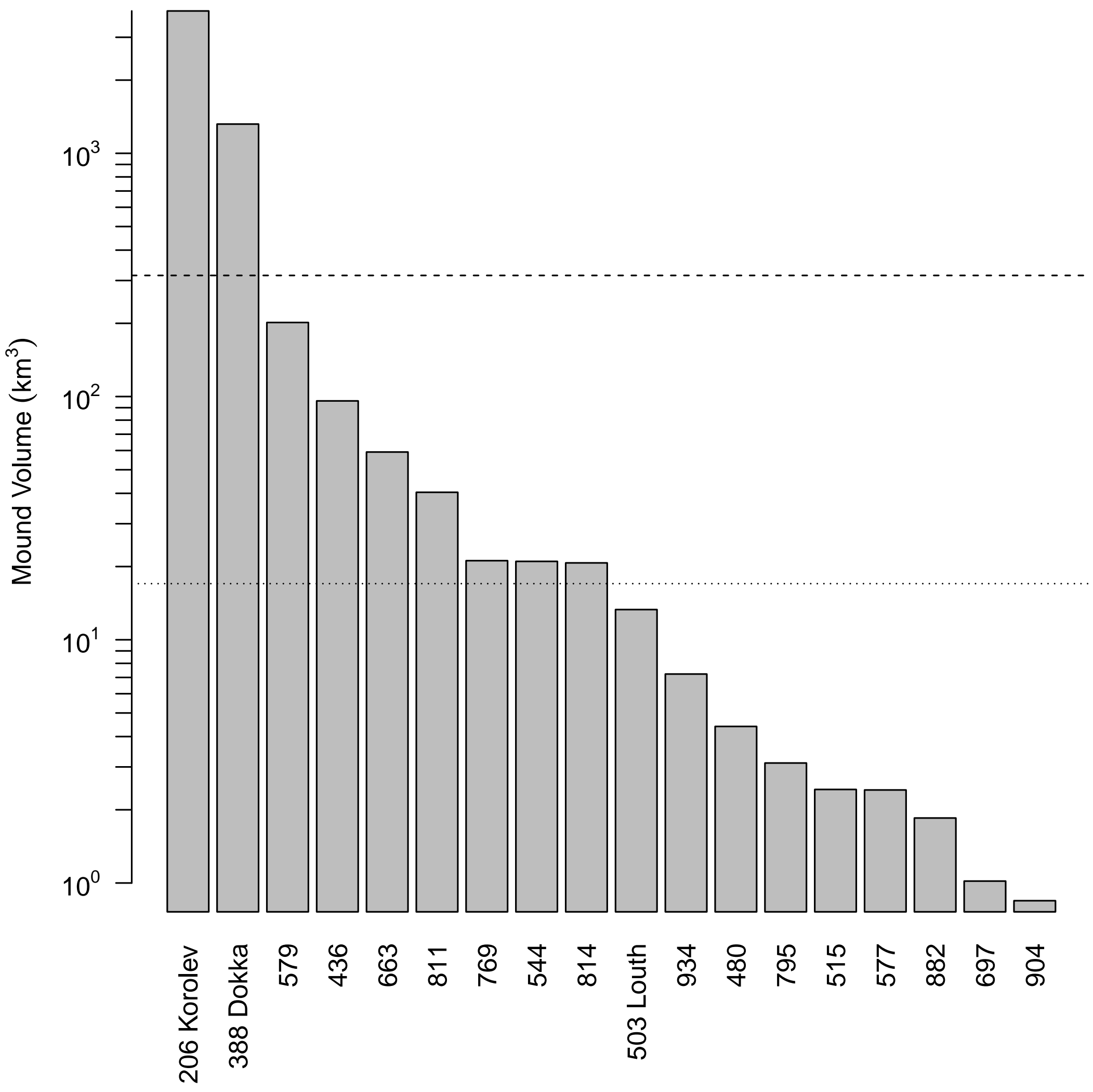


Figure 6 (black and white)
Click here to download hiq

Click here to download high resolution image

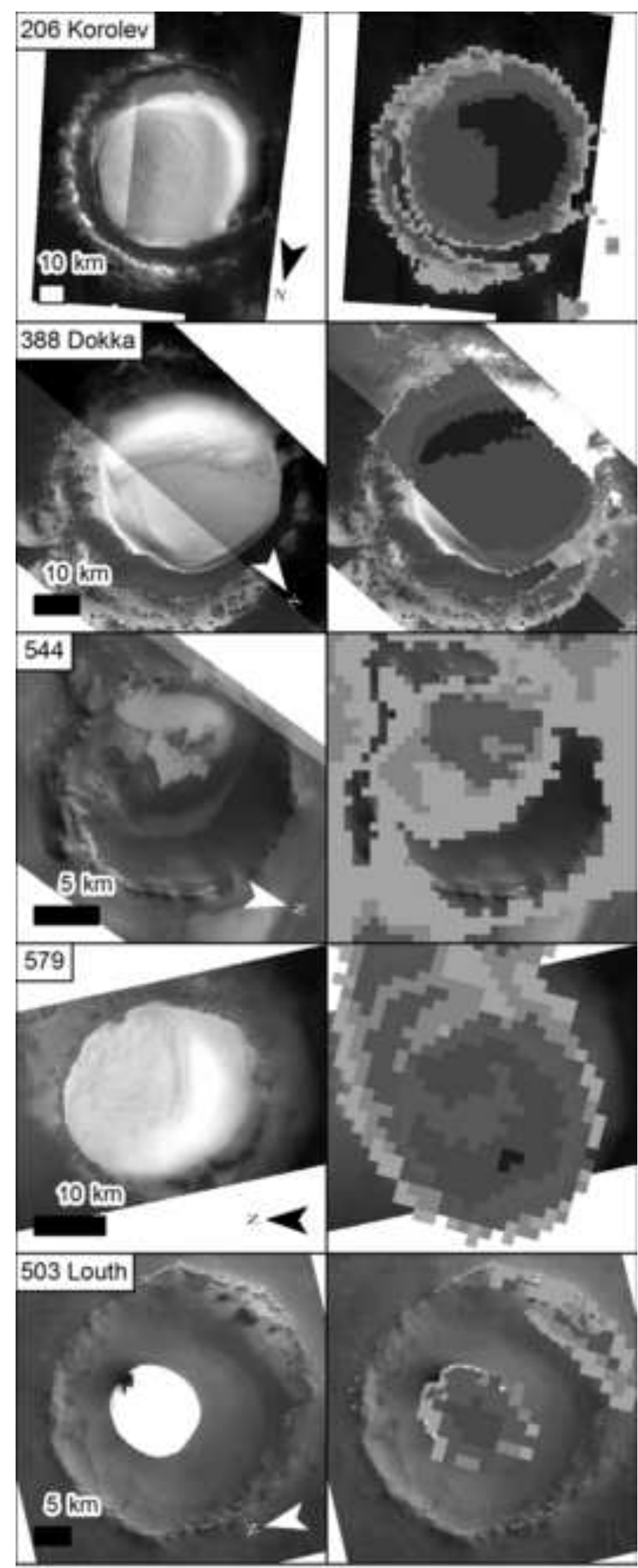

Water band-depth at $1500 \mathrm{~nm}$

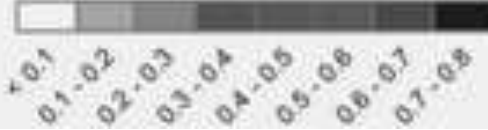

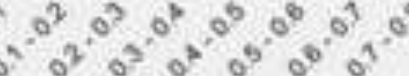


Figure 6
Click here to download high resolution image

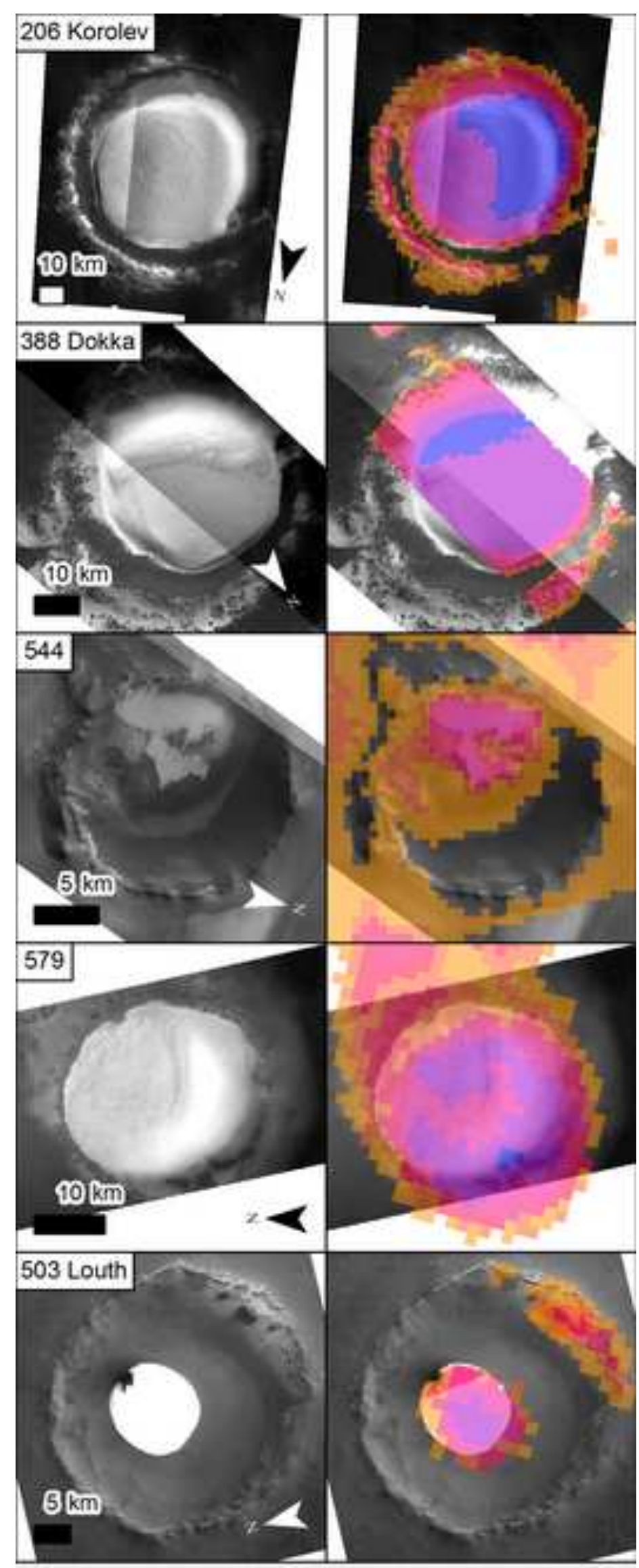

Water band-depth at $1500 \mathrm{~nm}$

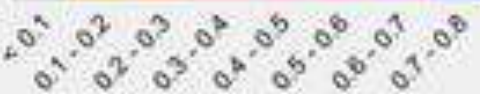


Figure 7 (black and white)

Click here to download high resolution image

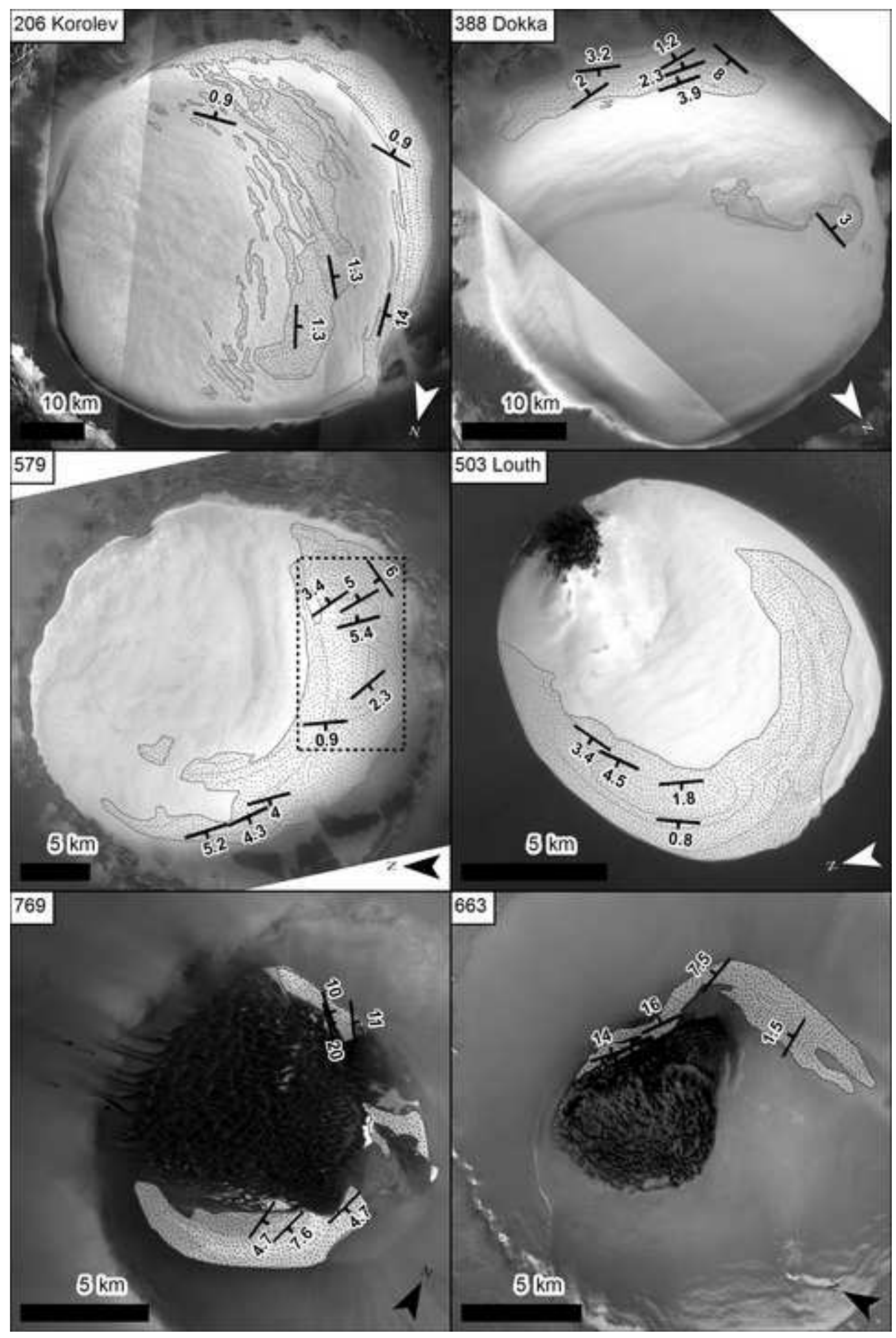




\section{Click here to download high resolution image}

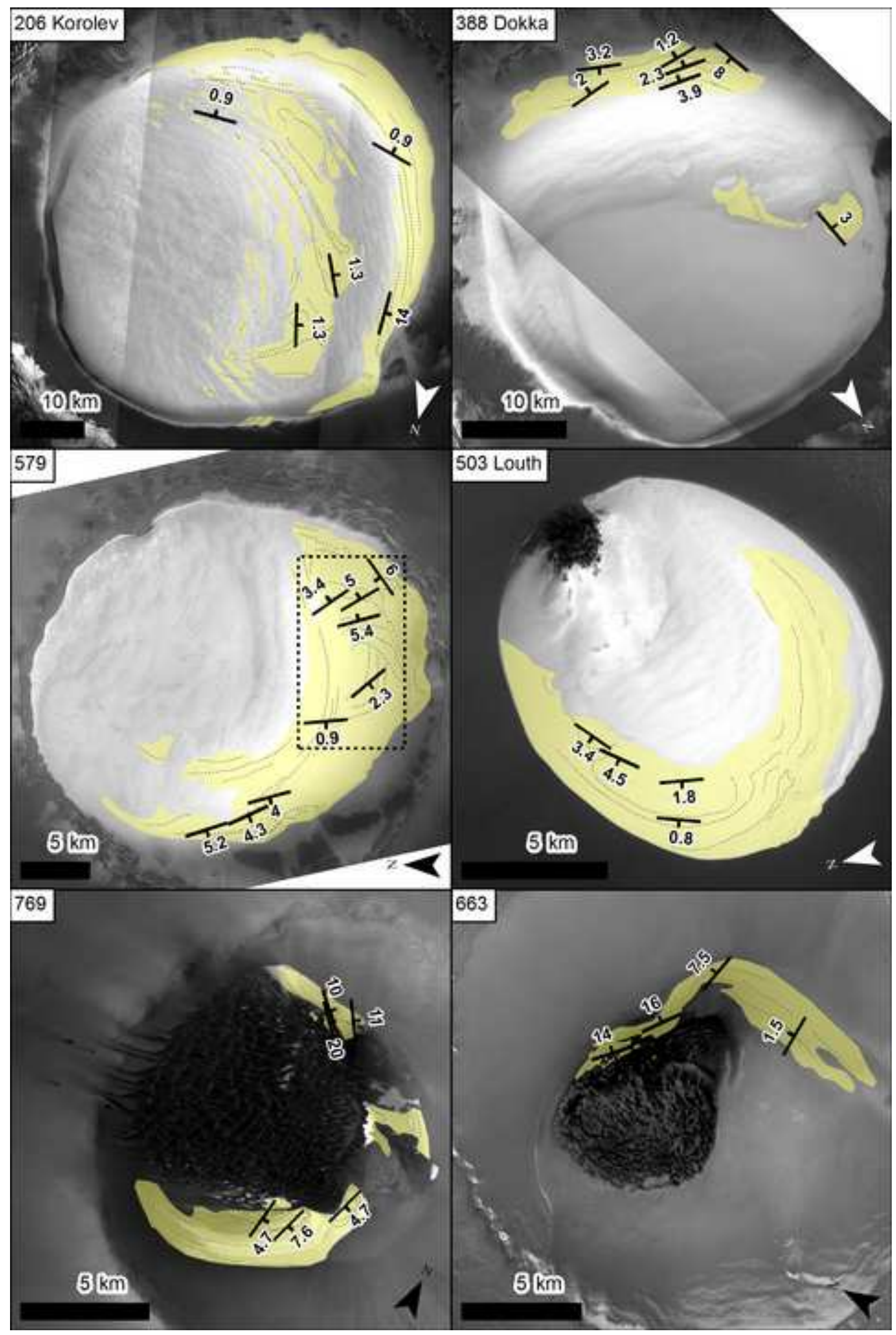


Click here to download high resolution image

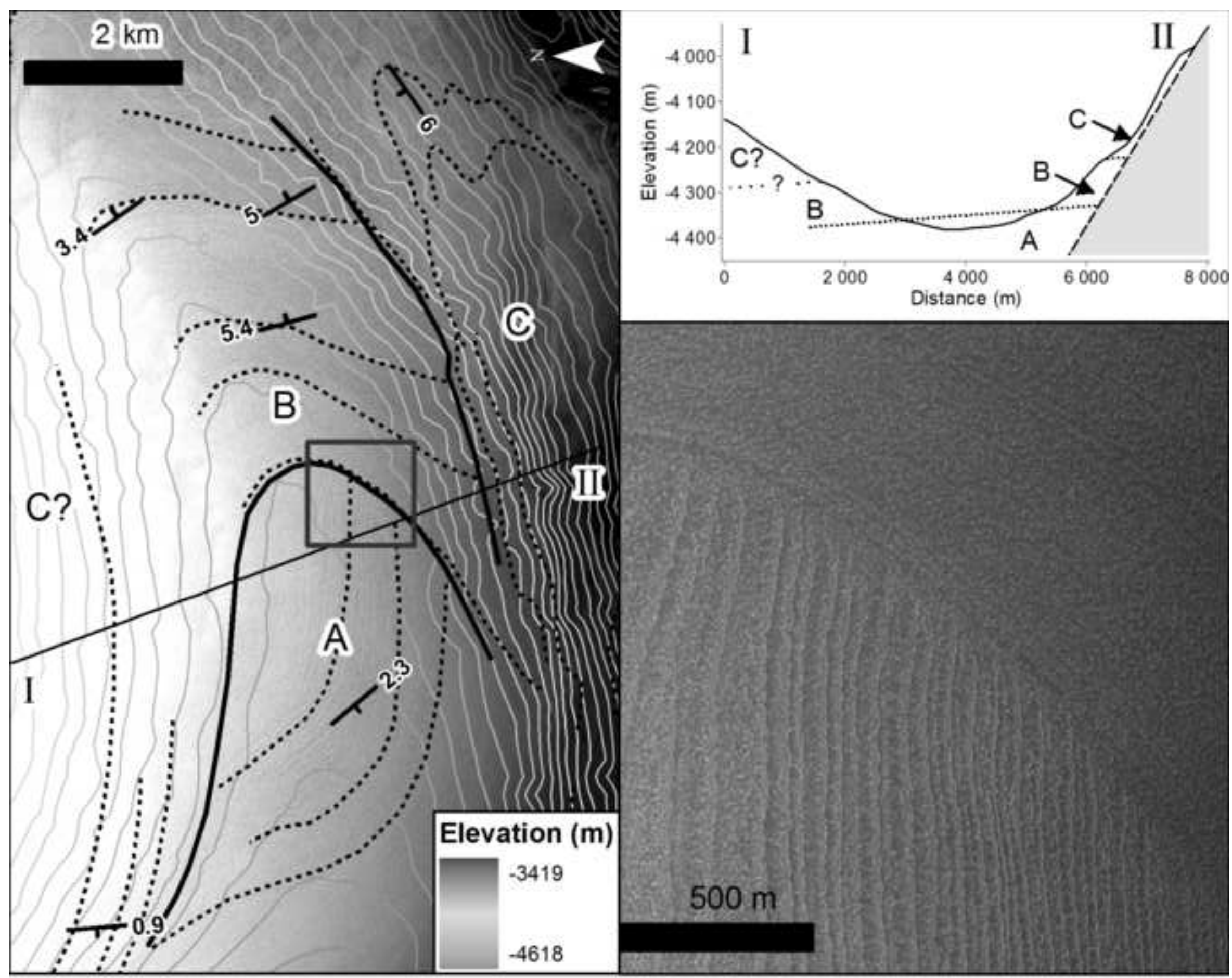




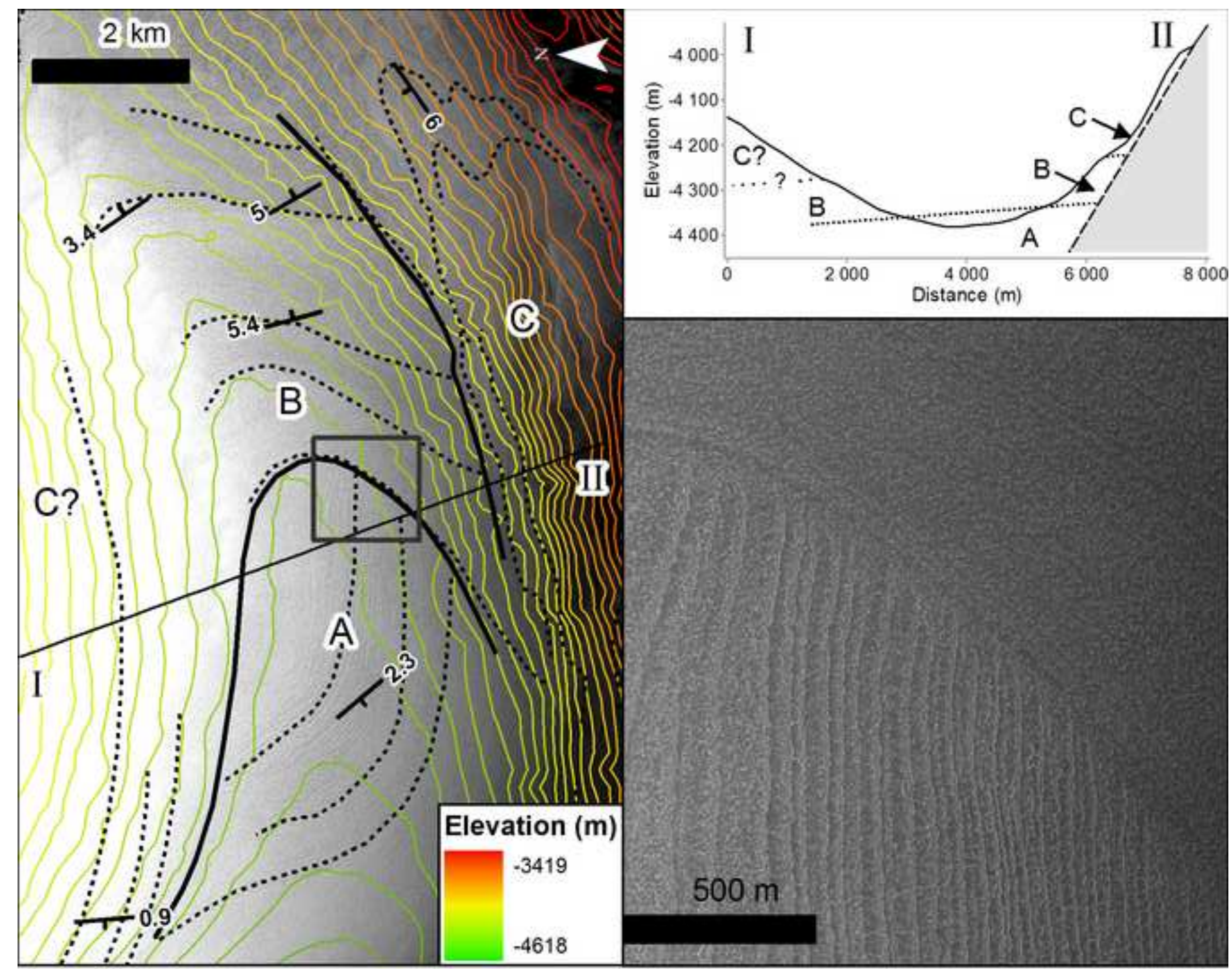


Figure 11 (black and white)
Click here to download high resolution image

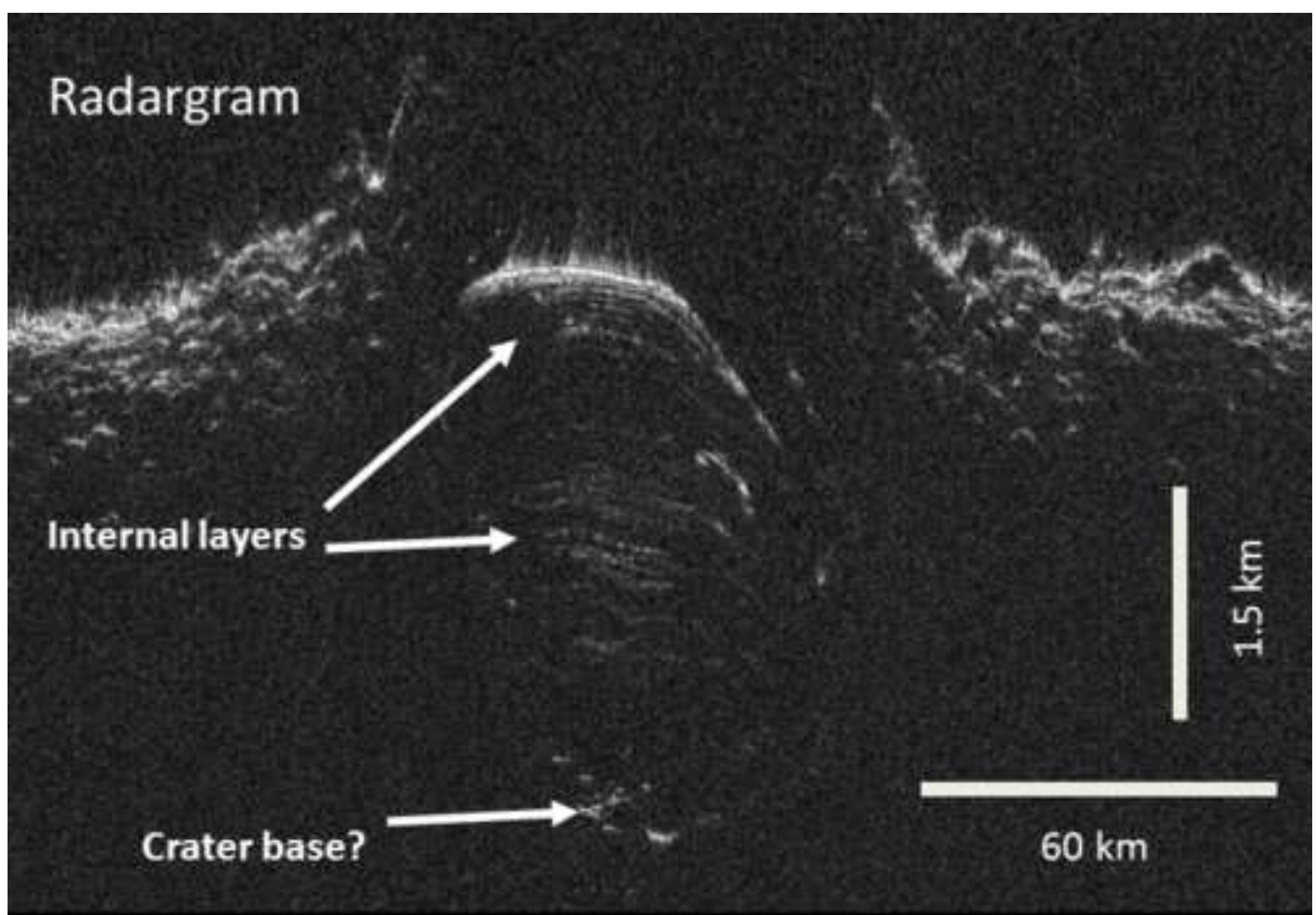

\section{Clutter}

\section{Simulation}

(4.
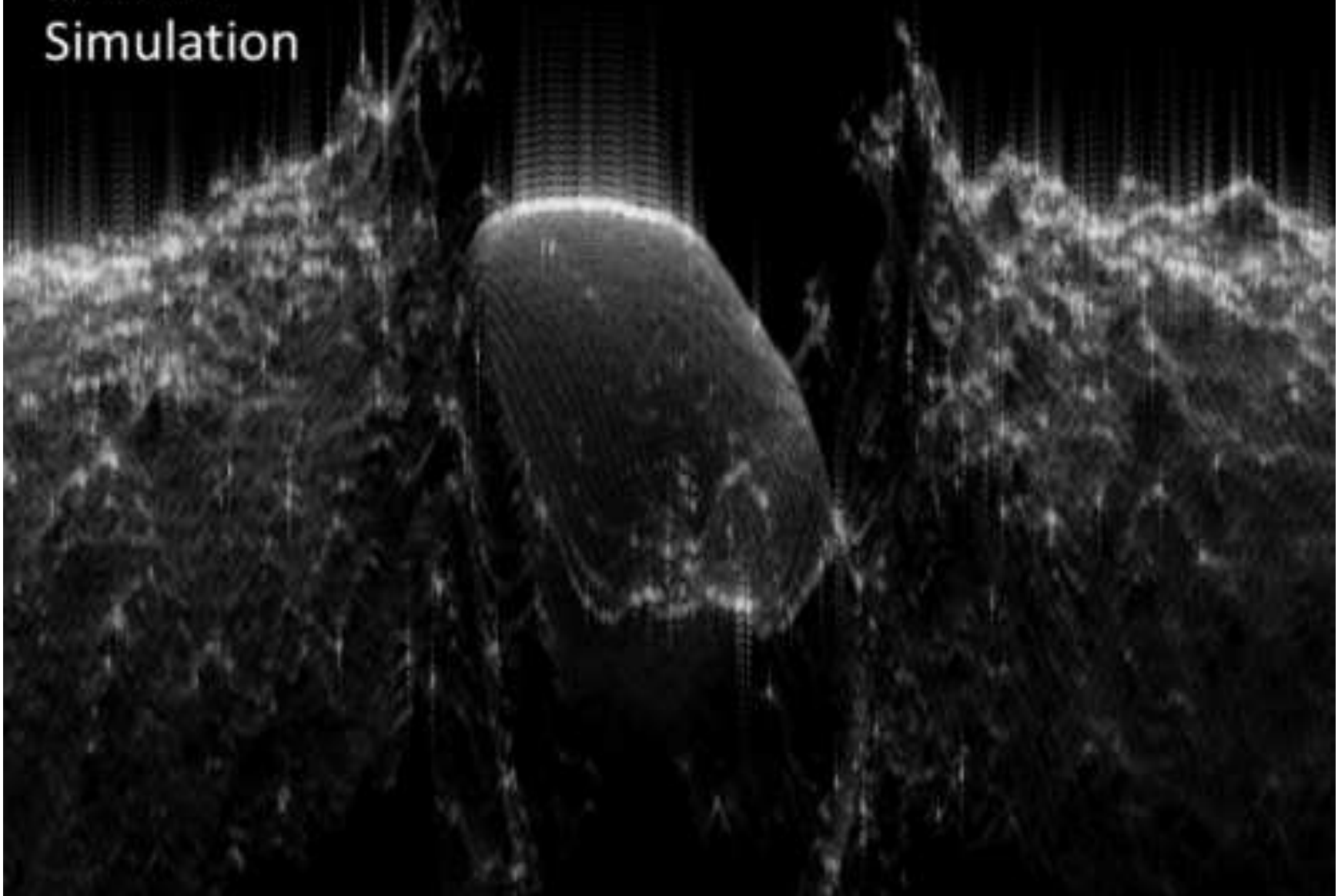


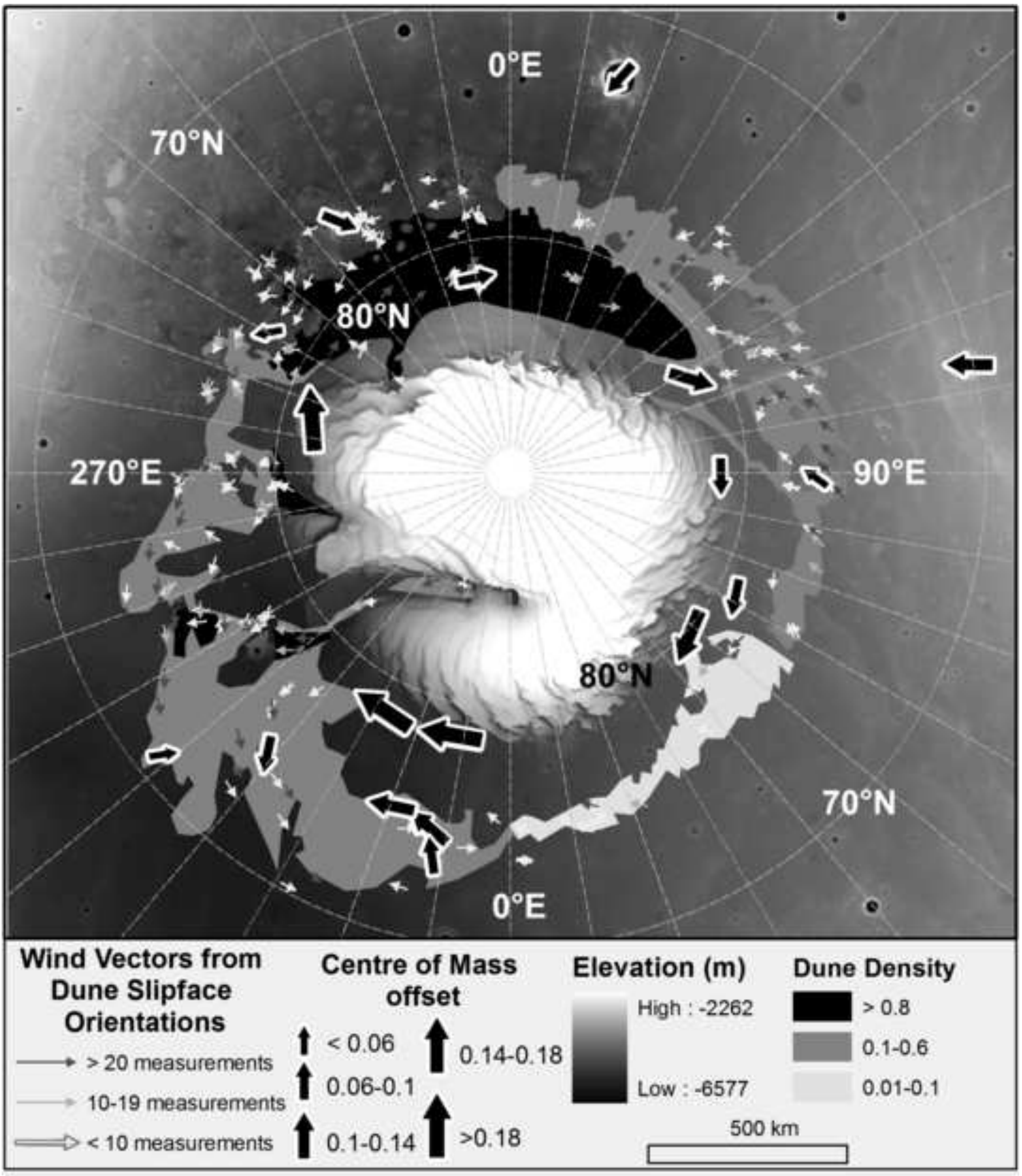




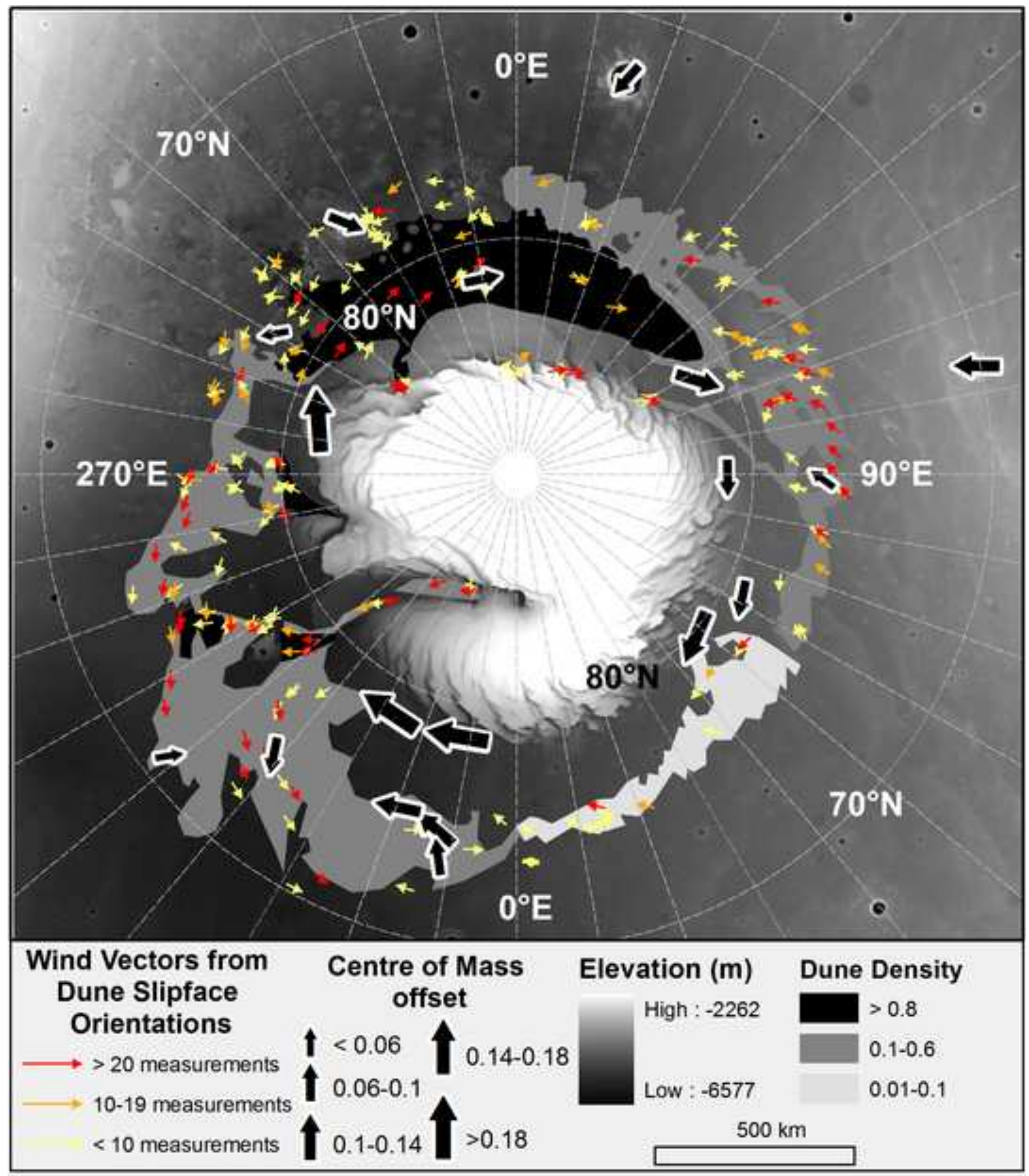




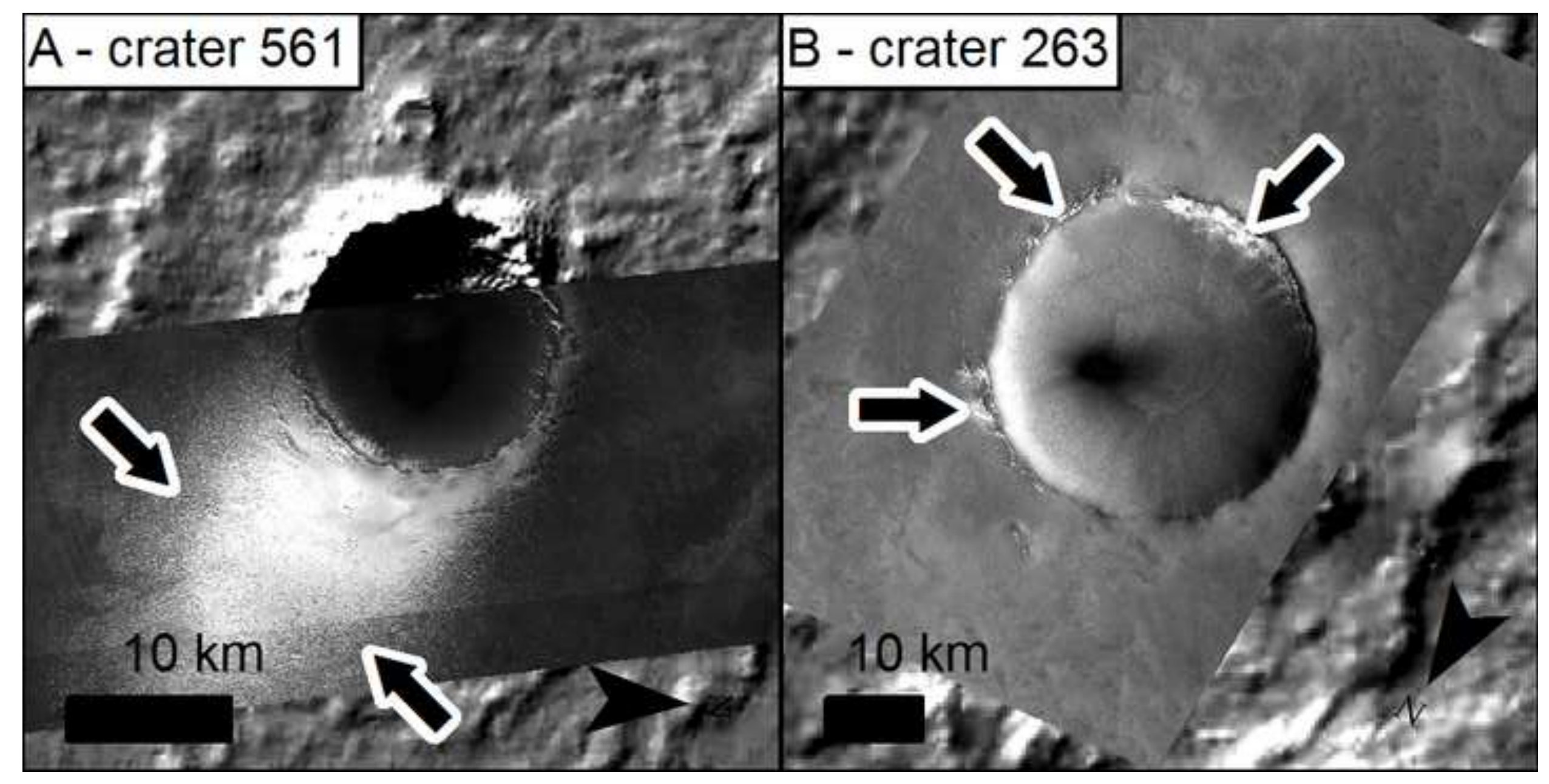


Figure 15 (black and white)
Click here to download high resolution image
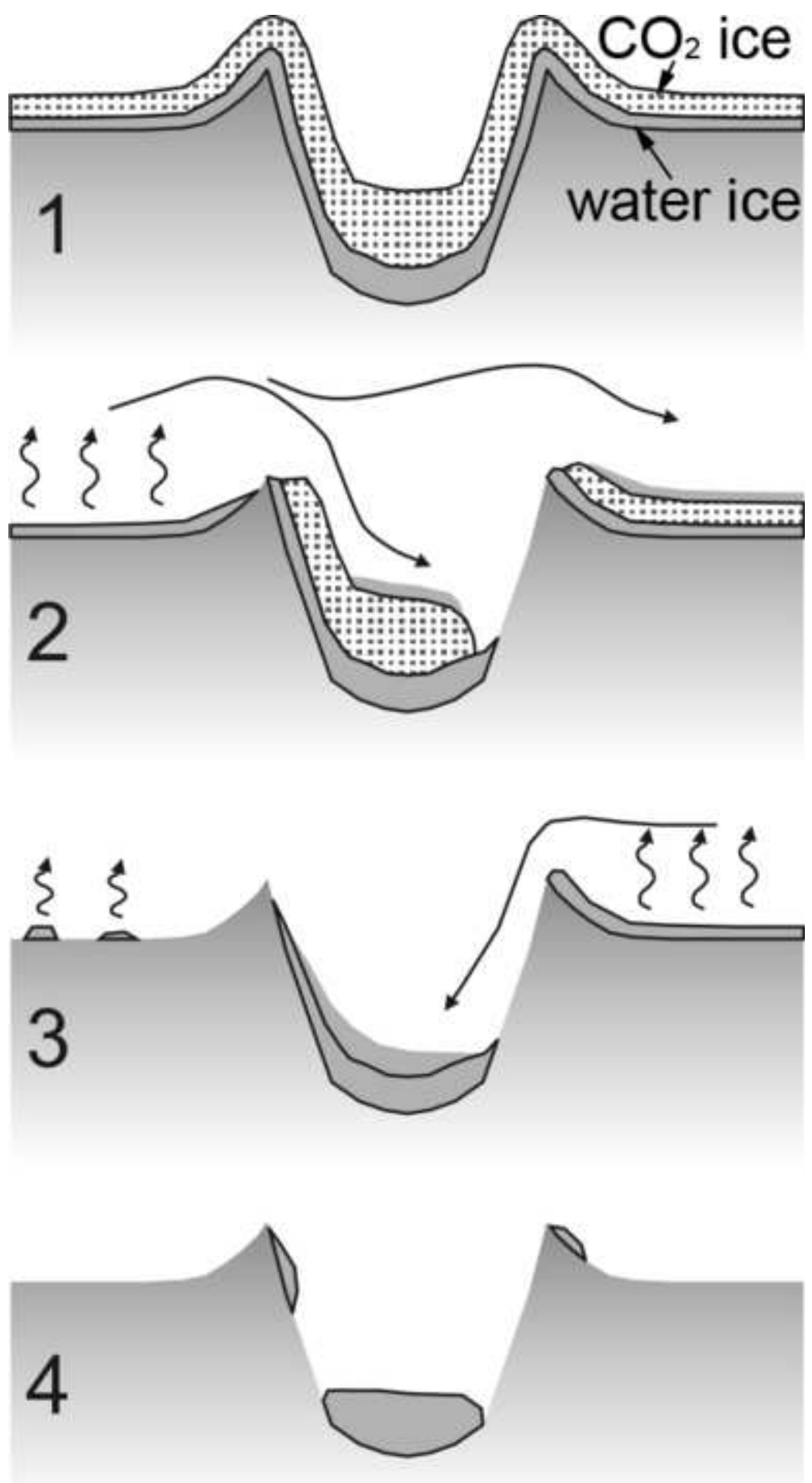
Figure 15
Click here to download high resolution image
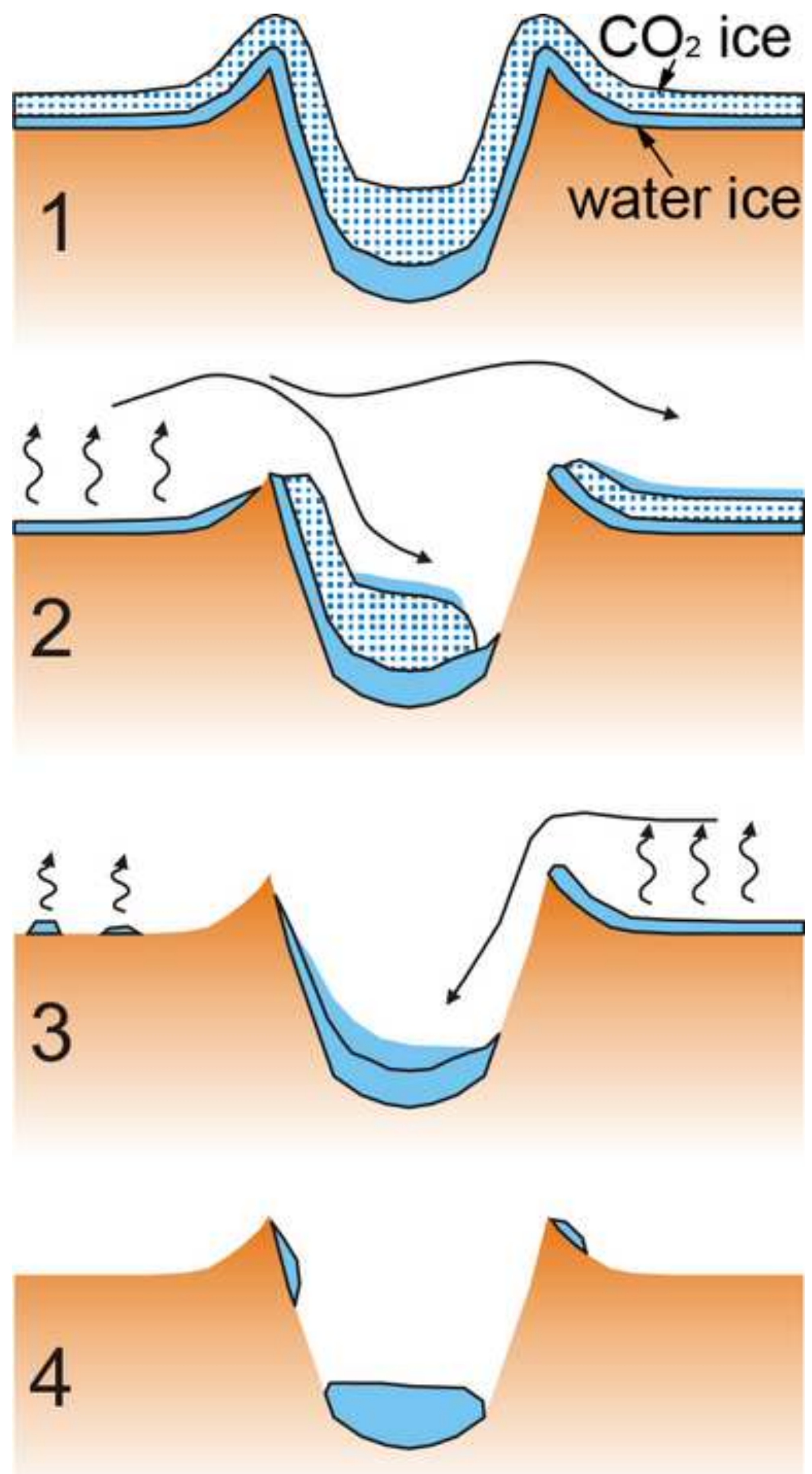
Click here to download high resolution image

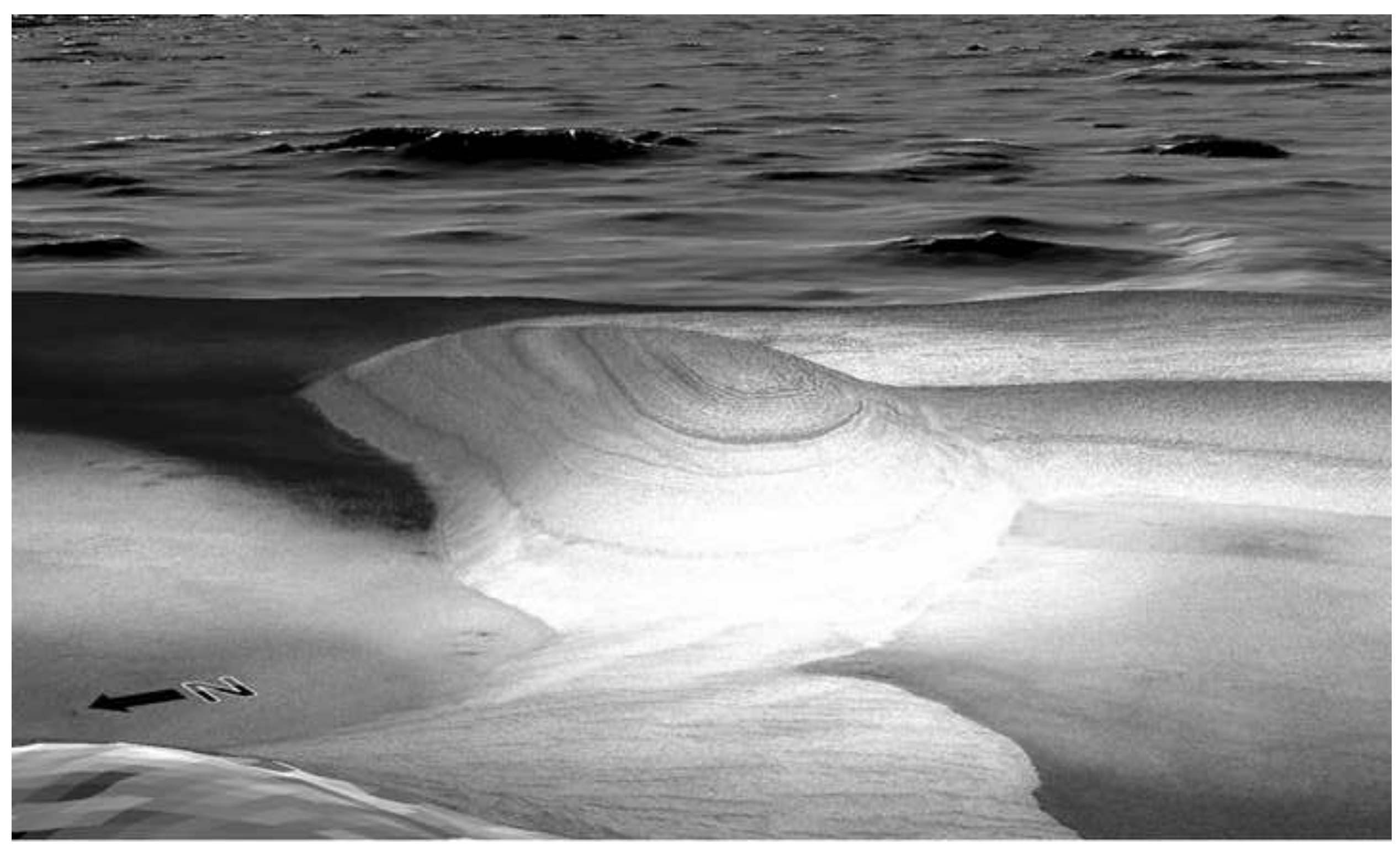


Sup. Mat. Fig. S1

Click here to download Supplementary Material for on-line publication only: AllCrossSections.tif (1) 作

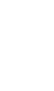

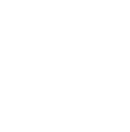

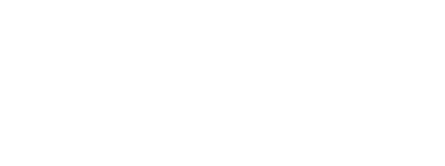
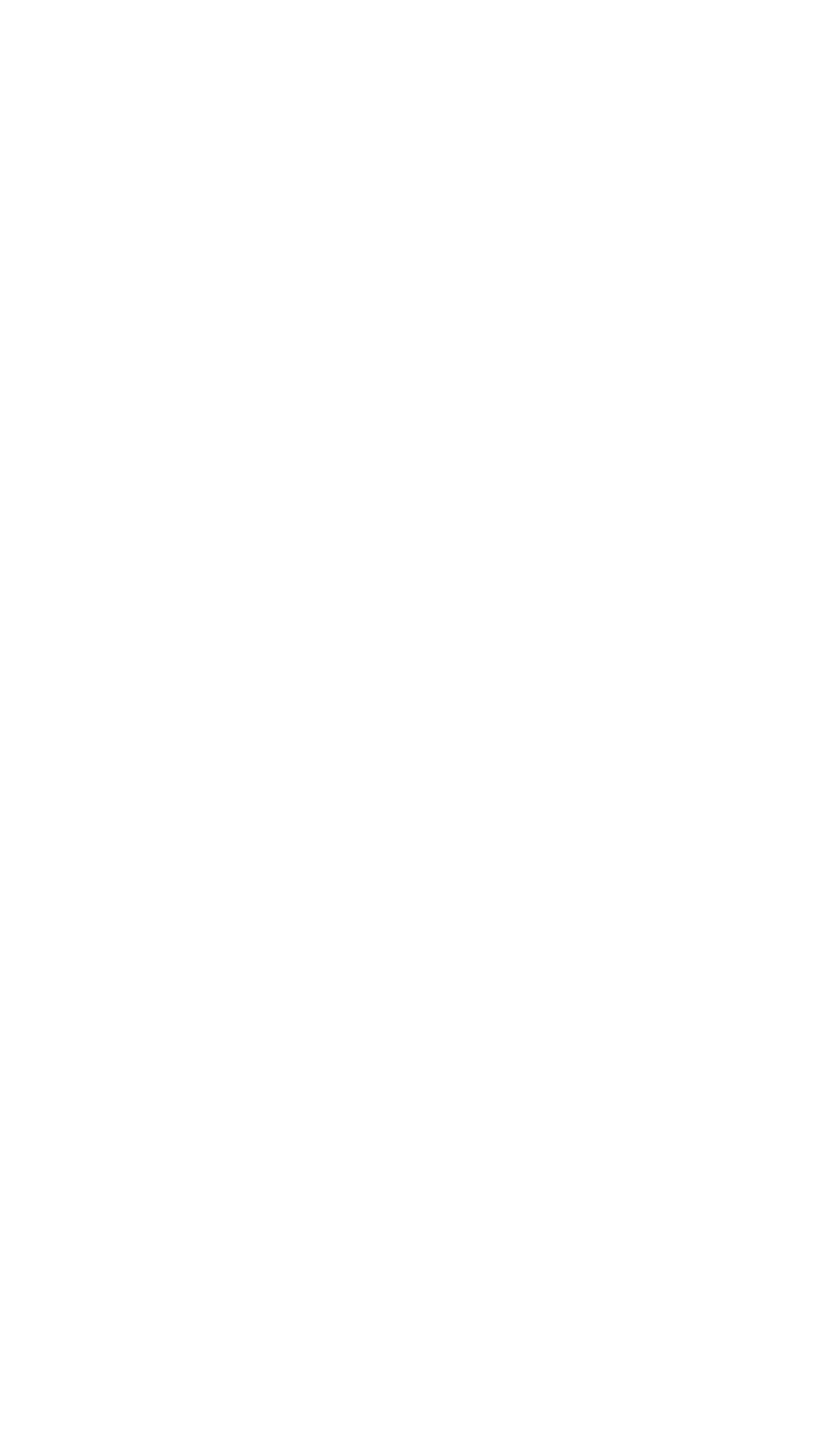